\title{
Genome-Wide mRNA Profiling Identifies X-BoX- Binding Protein 1 (XBP1) As An IRE1 And PUMA Repressor
}

\section{Magdalena Gebert}

Medical University of Gdansk: Gdanski Uniwersytet Medyczny

\section{Aleksandra Sobolewska}

Medical University of Gdansk: Gdanski Uniwersytet Medyczny

\section{Sylwia Bartoszewska}

Medical University of Gdansk: Gdanski Uniwersytet Medyczny

\section{Aleksandra Cabaj}

Nencki Institute of Experimental Biology Polish Academy of Sciences: Instytut Biologii Doswiadczalnej im Marcelego Nenckiego Polskiej Akademii Nauk

\section{David K. Crossman}

University of Alabama at Birmingham

\section{Jaroslaw Kroliczewski}

Medical University of Gdansk: Gdanski Uniwersytet Medyczny

\section{Piotr Madanecki}

Medical University of Gdansk: Gdanski Uniwersytet Medyczny

\section{Michal Dabrowski}

Nencki Institute of Experimental Biology PAS: Instytut Biologii Doswiadczalnej im Marcelego Nenckiego Polskiej Akademii Nauk

\section{James F. Collawn}

University of Alabama at Birmingham

Rafal Bartoszewski ( $\nabla$ rafalbar@gumed.edu.pl)

Medical Univeristy of Gdansk https://orcid.org/0000-0002-2864-6757

\section{Research Article}

Keywords: XBP1, UPR, ER stress, BBC3, ERN1, IRE1

Posted Date: May 27th, 2021

DOI: https://doi.org/10.21203/rs.3.rs-527235/v1 
License: (c) (i) This work is licensed under a Creative Commons Attribution 4.0 International License. Read Full License 


\section{Abstract}

Accumulation of misfolded proteins in ER activates the unfolded protein response (UPR), a multifunctional signaling pathway that is important for cell survival. The UPR is regulated by three ER transmembrane sensors, one of which is inositol-requiring protein 1 (IRE1). IRE1 activates a transcription factor, $\mathrm{X}$-box binding protein 1 (XBP1), by removing a 26-base intron from XBP1 mRNA that generates spliced $X B P 1 \mathrm{mRNA}(X B P 1 s)$. To search for XBP1 transcriptional targets, we utilized an XBP1s-inducible human cell line to limit XBP1 expression in a controlled manner. We also verified the identified XBP1dependent genes with specific silencing of this transcription factor during pharmacological ER stress induction with both an N-linked glycosylation inhibitor (tunicamycin) and a non-competitive inhibitor of the sarco/endoplasmic reticulum $\mathrm{Ca}^{2+}$ ATPase (SERCA) (thapsigargin). We then compared those results to the $X B P 1 s$-induced cell line without pharmacological ER stress induction. Using next-generation sequencing followed by bioinformatic analysis of XBP1 binding motifs, we defined an XBP1 regulatory network and identified XBP1 as a repressor of PUMA (a proapoptotic gene) and IRE1 mRNA expression during the UPR. Our results indicate impairing IRE1 activity during ER stress conditions accelerates cell death in ER stressed cells, whereas elevating XBP1 expression during ER stress using an inducible cell line correlated with a clear prosurvival effect and reduced PUMA protein expression. Although further studies will be required to test the underlying molecular mechanisms involved the relationship between these genes with XBP1, these studies identify a novel repressive role of XBP1 during the UPR.

\section{Introduction}

Endoplasmic reticulum (ER) stress can disrupt the folding and maturation of the secretory and membrane proteins and lead to the accumulation of unfolded proteins in the ER lumen, interruption of lipid synthesis, and deregulation of cellular calcium levels [1,2]. The buildup of misfolded proteins in ER leads to the activation of the unfolded protein response (UPR), a multifunctional signaling pathway that either promotes cell recovery [3], or initiates cell death if the ER stress remains unmitigated [4]. The UPR signaling pathways are initiated by three ER transmembrane sensors: inositol-requiring protein 1 (IRE1), protein kinase RNA-like ER kinase (PERK) and activating transcription factor 6 (ATF6). IRE1 removes a 26base intron from $X$-box binding protein 1 (XBP1) mRNA in an unconventional splicing reaction that results in translational frameshift that leads to the production of a functional and highly active spliced XBP1 (XBP1) transcription factor [5-9]. XBP1 enhances the expression of ER-resident chaperones and genes involved in ER-associated protein degradation (ERAD) [10] and promotes ER expansion [9]. The ER protein load is reduced by PERK-mediated phosphorylation of elF2a which inhibits most protein synthesis, by ERassociated degradation of misfolded proteins, and by IRE1-mediated mRNA cleavage and degradation [3]. However, if ER stress remains unmitigated, the UPR utilizes the same pathways to promote cell death by activating the intrinsic apoptotic pathways [11-16].

The interruption of the UPR transitions from pro-survival to apoptosis and the alteration of cell fate decisions contribute to the pathomechanisms of a number of human diseases including diabetes mellitus, cancer, and neurodegenerative and respiratory disorders [17]. To facilitate novel interventions for 
treating these disorders, it is important to understand the mechanisms governing the UPR pathways. Although we know the many of the details of the UPR pathways that contribute to cellular survival or apoptosis [18-20], it remains unclear how these signals determine the cell fate transitions in vivo. Part of this lack of clarity arises because the majority of the studies are based on pharmacological ER stressors that use different mechanisms for disturbing ER homeostasis and rely on models often utilizing high, non-physiological overexpression of UPR factors [21-23]. Furthermore, previous studies shown that UPR signaling has distinct consequences that ultimately depend on the nature and intensity of the stimulus as well as the specific cell type involved [18].

Although previous studies suggested that the transcriptional activity XBP1 is important in deciding cell fate in the UPR [24-29], the information regarding XBP1's direct role in modulating the transition between survival to apoptosis is limited. Therefore, the studies presented here were designed to select for XBP1specific transcriptional targets and their roles in cell fate decisions. In our approach, we used inducible human cell lines that allowed for comparable and controlled expression of spliced XBP1 and unspliced XBP1 proteins. We also verified the identified XBP1-dependent genes with specific silencing of this transcription factor during mild pharmacological ER stress induction with both an N-linked glycosylation inhibitor (tunicamycin, Tm) as well as a non-competitive inhibitor of the sarco/endoplasmic reticulum $\mathrm{Ca}^{2+}$ ATPase (SERCA) (thapsigargin, Tg). Using next-generation sequencing (NGS) followed by bioinformatic analysis of XBP1 binding motifs, and validation using XBP1-specific silencing and quantitative real-time PCR (qRT-PCR), we defined an XBP1-dependent regulatory network and identified XBP1 as a repressor of both PUMA and IRE1 expression during the UPR. This approach not only confirmed previously known XBP1 roles during UPR, but also resulted in identification of novel targets of this transcription factor that could fine tune cell fate decisions. Furthermore, we show that XBP1 can modulate the PERK pathway activity via modulation of both $\mathrm{CHOP}$ and growth arrest and DNA damageinducible protein (GADD34) mRNA expression. Although further studies will be required to test the underlying molecular mechanisms involved the relationship between these genes with XBP1, the studies presented here identify a novel regulatory role of XBP1 during the UPR.

\section{Materials And Methods}

Cell lines and culture conditions. HeLa S3 cells were obtained from the American Type Culture Collection (CCL-2.2; Manassas, VA, USA). Cells were cultured in Minimum Essential Modified Eagle's Medium (Thermo Fisher Scientific, Waltham, MA, USA) with $2 \mathrm{mM} \mathrm{l-glutamine} \mathrm{(MilliporeSigma,} \mathrm{Burlington,} \mathrm{MA,}$ USA), antibiotics ( $100 \mathrm{U} / \mathrm{ml}$ of penicillin and $100 \mu \mathrm{g} / \mathrm{ml}$ of streptomycin (MilliporeSigma), and $10 \%$ fetal bovine serum in a humidified incubator at $37^{\circ} \mathrm{C}$ in $5 \% \mathrm{CO}_{2}$ in 6-well plates. Cells were allowed to grow to $70-80 \%$ confluence before the start of the experiments.

The inducible HeLa S3 XBP1s and XBP1 $u$ cell lines were constructed beginning with vectors containing the cDNA sequences of XBP1s (NM_001079539.1) and XBP1U (NM_005080.3) that were obtained from GeneCopoeia (Rockville, MD, US; XBP1s cat. no. EX-Z4299 and XBP1u cat. no. EX-F0758). The ORFs sequences were verified with Sanger sequencing, and $X B P 1 s$ and $X B P 1 U$ cDNAs were restricted with 
EcoRI/Mlul and EcoRI/BamHI, respectively, and cloned into the pCW57-MCS1-P2A-MCS2 (Hygro) vector that permits doxycycline-controlled inducible lentiviral expression [30]. pCW57-MCS1-P2A-MCS2 (Hygro) was a gift from Adam Karpf (Addgene plasmid \# 80922; http://n2t.net/addgene:80922). The correct pCW57-XBP1s and pCW57-XBP1 $u$ insert sequences were verified with Sanger sequencing. These vectors along with VSV-G envelope expressing plasmid (pMD2.G) and lentiviral packaging plasmid (psPAX2) were used to transfect HEK-293 cells (ATCC CRL-1573) to generate lentiviruses carrying the XBP1s or $X B P 1 u$ transgenes. The PMD2.G and psPAX2 plasmids were a gift from Didier Trono (Addgene plasmid \# 12259; http://n2t.net/addgene:12259 and Addgene plasmid \# 12260; http://n2t.net/addgene:12260, respectively). The lentiviruses were also used to transduce Hela S3 cells [31, 32]. Finally, following hygromycin b selection ( $300 \mu \mathrm{g} / \mathrm{ml}$, Sigma) and qPCR verification of $24 \mathrm{~h}$ doxycycline induction (400 $\mu \mathrm{g} / \mathrm{ml}$, D3072 MilliporeSigma) of XBP1s and XBP1u mRNAs in HeLa S3 cells, two stable clonal cell lines capable of stable inducible expression of XBP1s (Hela-XBP1s) and XBP1u (HeLa-XBP1u) were obtained. These cell lines were cultured in Minimum Essential Modified Eagle's Medium with $2 \mathrm{mM}$-glutamine, hygromycin B $(300 \mu \mathrm{g} / \mathrm{ml})$ and $10 \%$ tetracycline free fetal bovine serum (Takara Bio, USA) in a humidified incubator at $37^{\circ} \mathrm{C}$ in $5 \% \mathrm{CO}_{2}$ in 6 -well plates. Cells were allowed to grow to $70-80 \%$ confluence before the start of the experiments.

Induction of ER stress and activation of the UPR. Pharmacological induction of ER stress and activation of the UPR were performed as we previously described [21]. Briefly, cells were treated with the compounds for the time periods specified: tunicamycin (Tm, $2.5 \mu \mathrm{g} \cdot \mathrm{mL}^{-1}$ or $0.5 \mu \mathrm{g} \cdot \mathrm{mL}^{-1}$; Sigma, T7765), thapsigargin (Tg, $50 \mathrm{nM}$ or $2.5 \mathrm{nM}$; Sigma, T9033). CTRL cells were treated with vehicle CTRL, DMSO ( $<0.5 \% \mathrm{v} / \mathrm{v}$; Sigma, D2650). Furthermore, to verify IRE1 activity, cells treated were $20 \mu \mathrm{M} 4 \mu 8 \mathrm{C}$ (an IRE1 inhibitor, Sigma-Aldrich, SML0949) dissolved in DMSO (Sigma-Aldrich, St. Louis, MI, USA) [33].

Real time cell viability assay. For real-time monitoring of cell viability, we applied the xCELLigence system as we described previously [34]. Briefly, HeLa cells (12 000 cells per well) were seeded in the 16-well PC plates (00300600890, ACEA Biosciences Inc., San Diego, CA, USA) $24 \mathrm{~h}$ prior to the experiment. CTRL cells were cultured in the presence of DMSO vehicle. Treated cells were incubated with ER stressors for the next $24 \mathrm{~h}$, and every $15 \mathrm{~min}$, the cell conductances (cell index) were recorded. All experiments were performed in triplicate with three independent repeats. RTCA software v. 1.2.1 (ACEA Biosciences, Inc, San Diego, CA, USA) was used to calculate the normalized cell index and the cell growth curve slopes.

Monitoring caspase 3 and caspase 7 activity. The caspase 7 is considered to be redundant with caspase 3 because these enzymes share an optimal peptide recognition sequence and have several endogenous protein substrates in common [35]. While our main goal was to assess caspase 3 activity, the commercially available assays do not distinguish between these two cysteine proteases. Hence, we applied the caspase-Glo 3/7 assay (Promega, Madison, WI, USA) to measure relative caspase activity as described previously [21,34]. Briefly, cells the day after transfection with the specified siRNA were seeded onto 96-well luminescence assay white plates with clear bottoms (Corning Inc., 3903). The next day, the cells were treated with ER stressors or vehicle $(0.1 \% \mathrm{DMSO})$ for indicated time points. Following treatment, cells were washed with PBS and the Caspase-Glo 3/7 assays (Promega) were performed in 
accordance with the manufacturer's instructions using the GloMax-Multi + Detection System (Promega). The results were normalized to the values obtained from the vehicle control treatments.

siRNA transfections. siRNAs against XBP1 (Ambion assay id s14915) and BBC3 (Ambion assay id s25840) were purchased from Ambion. HeLa cells were transfected using the Lipofectamine RNAiMax (Invitrogen, 13778030) according to manufacturer's protocol. The siRNAs were used at final concentrations of $30 \mathrm{nM}$. The transfected cells were cultured for 2 days prior to further analysis. Ambion siRNA Negative Control 1 (Ambion assay id MC22484) was used as a control.

Isolation of RNA. Total RNA (containing both mRNA and miRNA) was isolated using miRNeasy kit (Qiagen). RNA concentrations were calculated based on the absorbance at $260 \mathrm{~nm}$. RNA samples were stored at $-70^{\circ} \mathrm{C}$ until use.

Next-generation RNA sequencing analyses. The RNA isolation and analyses were performed in HeLa $X B P 1 s$ and XBP1 $u$ cells. Briefly, following XBP1 induction with doxycycline $(24 \mathrm{~h}$ and $400 \mu \mathrm{g} / \mathrm{ml}$ final concentration) total RNA isolation, samples were validated with qRT-PCR for ER stress activation prior to further analysis. Following rRNA depletion, the remaining RNA fraction was used for library construction and subjected to 100-bp single-end sequencing on an Illumina HiSeq 2000 instrument (San Diego, CA, USA). Sequencing reads were aligned to the Gencode human reference genome assembly (GRCh38 p7 Release 25) using STAR [36]. Transcript assembly and estimation of the relative abundance and tests for differential expression were carried out with Cufflinks and Cuffdiff [37]. The resulting data were validated with qRT-PCR. The heat map generation and hierarchical clustering were performed with the Morpheus Web server (Morpheus, https://software.broadinstitute.org/morpheus). The Enrichr Web server (https://amp.pharm.mssm.edu/Enrichr/) [38] was applied to assign the NGS results into the 'Gene Ontology Biological Process' categories with the selection based on a False Discovery Rate $Q$-value $\mathrm{q}<$ 0.05 . Furthermore, the analyses were limited to experimentally verified interactions and no extended gene enrichment set analyses were performed.

Measurement of mRNA quantitative Real Time PCR (qRT-PCR). We used TaqMan One-Step RT-PCR Master Mix Reagents (Applied Biosystems) as described previously [39-41] using the manufacturer's protocol (retrotranscription: $15 \mathrm{~min}, 48^{\circ} \mathrm{C}$ ). For NGS data validation, 96 custom TaqMan expression array plates (id) were used according to manufacturer's instructions. The relative expressions were calculated using the $2^{-\triangle \triangle C t}$ method [42] with the Glyceraldehyde 3-phosphate dehydrogenase (GAPDH), and neutral ribosomal phosphoprotein PO (RPLPO) genes as reference genes for the mRNA. TaqMan probes ids used are provided in Supplemental Table 1.

Western Blots. The XBP1 protein detection was performed as described in [43]. Briefly, cells were lysed on ice for $15 \mathrm{~min}$ in RIPA buffer [ $150 \mathrm{mM} \mathrm{NaCl}, 1 \% \mathrm{NP}-40,0.5 \%$ sodium deoxycholate, $0.1 \%$ SDS, and $50 \mathrm{mM}$ Tris- $\mathrm{HCl}(\mathrm{pH} 8.0)$ ] supplemented with Protease Inhibitor Complete Mini (000000011836170001; Roche, Basel, Switzerland). The insoluble material was removed by centrifugation at 15,000 $g$ for $15 \mathrm{~min}$. Protein concentrations were determined by Bio-Rad Protein Assay [Bradford-based method; Bio-Rad, Hercules, 
CA, USA] using bovine serum albumin (BSA; MilliporeSigma) as the standard. Following the normalization of protein concentrations, lysates were mixed with an equal volume of 2 times Laemmli sample buffer (Bio-Rad) and incubated for $5 \mathrm{~min}$ at $95^{\circ} \mathrm{C}$ before separation by SDS-PAGE on stain-free TGX gradient gels (Bio-Rad). Following SDS-PAGE, the proteins were transferred to PVDF membranes (300 mA for $90 \mathrm{~min}$ at $4^{\circ} \mathrm{C}$ ). The membranes were then blocked with BSA dissolved in PBS and Tween-20 (3\% BSA and $0.5 \%$ Tween-20 for $1-2 \mathrm{~h}$ ) followed by immunoblotting with the primary antibody for each experiment for XBP1 (mAb 12782; diluted at 1:1000; Cell Signaling Technology, Danvers, MA, USA) or XBP1 (NBP1-77681; diluted at 1:700; Novus Biological USA). For PUMA, the monoclonal antibody MBS9131466 (MyBioSource Inc. San Diego, CA USA) was used for overnight incubations at 1:1500 dilution. After the washing steps, the membranes were incubated with goat anti-rabbit lgG $(\mathrm{H}+\mathrm{L})$ horseradish peroxidase-conjugated secondary antibodies (Bio-Rad) and detected using ECL (Amresco, Solon, OH, USA). Densitometry was performed using Image Lab software v.4.1 (Bio-Rad).

XBP1 motif analysis. The promoters of the gene transcripts that were affected by $X B P 1$ induction in the NGS experiments were analyzed for XBP1 binding sites. We used the XBP1 binding motif M00402 (consensus: GACGTGkCmtww, where $\mathrm{k}=\mathrm{G}$ or $\mathrm{T} ; \mathrm{m}=\mathrm{A}$ or $\mathrm{C} ; \mathrm{w}=\mathrm{A}$ or $\mathrm{T}$ ) from the Hocomoco v. 9 motif library [44]. This motif is based on analysis of published XBP1 ChIP-seq data in three human cancer cell lines [45]. Instances of the XBP1 motif were found with the program matrix-scan (quick) [46] using the pre-computed first order Markov-chain background model. The motif scores were converted to $P$-values and a stringent $\mathrm{p}$-value threshold of $P<0.0001$ was used to call an instance of XBP1 motif at a given genomic position. In each gene promoter sequence that was defined as a $20 \mathrm{~kb}$ window around the TSS, we examined only the open chromatin regions that were established in the HeLa S3 cell line by the ENCODE[47] project. We merged both DNase I-seq HeLa datasets found in Ensembl [48] (v.79). We used the Nencki Genomics Database [49] (v. 79_1) to obtain genomic coordinates of these motif instances. For each gene, we calculated the number of instances found in the open chromatin regions.

Statistical analysis. Results were expressed as a mean \pm standard deviation. Statistical significance was determined using the Student's t-test and ANOVA on ranks with p-values $P \leq 0.05$ considered significant. The correlation was accessed via the Pearson product-moment correlation method.

\section{Results}

Since our working hypothesis was that the commonly used concentrations of ER stressors lead to nonphysiological elevation of UPR signals and the potential for misassignment of UPR pathways targets or their role in cell fate decisions, we compared commonly used classical pharmacological stressors at high concentrations (high stress) and at low concentrations (low stress). We tested a glycosylation inhibitor tunicamycin $(\mathrm{Tm})$ that is normally used at $2.5 \mu \mathrm{g} / \mathrm{ml}$ and a noncompetitive inhibitor of the sarco/endoplasmic reticulum $\mathrm{Ca}^{2+}$ ATPase thapsigargin that is normally used at $\mathrm{Tg}, 50 \mathrm{nM}$ (high stress). For the low stress model, we used $\mathrm{Tm}$ at $0.5 \mu \mathrm{g} / \mathrm{ml}$ and $\mathrm{Tg}$ at $2.5 \mathrm{nM}$. These concentrations were determined experimentally as the lowest concentrations that were able to induce $X B P 1, \operatorname{HSPA5}(B i P)$ and 
DITT3 (also known as CHOP) mRNAs by at least 2-fold after 6 hours of treatment. We used HeLa cells since this a common model system that has been employed in ER stress and UPR studies [50-53].

As shown in Fig. 1, both stress models were able to induce both pro-survival and apoptotic reporters. The adaptive BiP chaperone mRNA levels (HSPA5) was continuously elevated in both the high and low stress models (Fig. 1A). High ER stress was effectively induced with the commonly used $\mathrm{Tm}$ and $\mathrm{Tg}$ concentrations $(2.5 \mathrm{\mu g} / \mathrm{ml}$ and $50 \mathrm{nM}$ respectively) [21, 43, 51]. High stress resulted in a 10- and 15-fold induction of HSPA5 mRNA with Tm and Tg, respectively, after 6 hours and remained elevated after 12 hours of treatment. In contrast, during mild ER stress conditions after 6 hours, the HSPA5 mRNA was induced by $\sim 3$-fold by both $\mathrm{Tm}$ and $\mathrm{Tg}$, and this dramatically increased after 12 hours of treatment (Fig. 1A). The pro-apoptotic DDIT3 (CHOP) mRNA levels were also elevated 18- and 6-fold with Tm and Tg treatment, respectively, after 6 hours of low stress conditions and remained elevated after 12 hours (Fig. 1B). The use of the higher concentrations of Tm and Tg resulted in $\sim 40$ - and $\sim 35$-fold inductions of DDIT3 (CHOP) mRNA expression after both 6 and 12 hours. A similar pattern of high and low stress treatments was seen with XPB1s (Fig. 1C) and DNAJB9 (Fig. 1D) mRNAs in that they were induced less during the low stress conditions as might be expected. Interestingly, the XBP1s mRNA levels decreased after 12 hours, whereas all the other mRNAs either increased or remained the same after high and low stress conditions. The DNAJB9 (DnaJ heat shock protein family (Hsp40) member B9) mRNA levels, a proadaptive chaperone and an XBP1 transcriptional target, was elevated as expected under both high and low stress conditions (Fig. 1D). Furthermore, ERN1 (IRE1) mRNA expression was induced after 6 hours only by higher Tm and Tg concentrations, whereas in mild stress, ERN1 mRNA was only elevated by Tm treatment after 12 hours (Fig. 1E).

We next tested the effects of high and low stress on cell viability and proliferation. As shown in Fig. 1F, the Tm treatments at high and low stress conditions elevated caspase $3 / 7$ activity at 12 and 24 hours, whereas the $\mathrm{Tg}$ treatment elevated the caspase activity only at 24 hours during high stress conditions (Fig. 1F). The lack of significant apoptotic signal for the lower Tg concentration was consistent with lower induction of apoptotic mRNAs. These observations were also consistent with the results of real time monitoring of HeLa cell proliferation (Fig. 1G). The mild ER Tg-induced stress had no significant effect on HeLa proliferation up to 36 hours, while treatment with higher Tg concentration significantly limited cells growth throughout the entire time course. Whereas, both Tm concentrations affected on HeLa growth and demonstrated a clear indication of apoptosis after 18 hours (Fig. 1G). Taken together, the data illustrate that lower stress conditions still activate the UPR and may provide a more physiological model to delineate the differences between the adaptive and apoptotic UPR signaling pathways.

To follow XBP1's role in the UPR, we created an inducible HeLa cell line model in which we could express low mRNA levels of this transcription factor that might mimic the levels observed during mild ER stress. Following the expansion and validation of individual clones expressing XBP1s under an inducible promoter, we selected a cell line that upon induction, stably expressed about an 11-fold increase XBP1s mRNA (HeLa-XBP1s) when compared to non-induced cells (Fig. 2A). The obtained XBP1 levels were 
sufficient to induce the expression of DNAJB9 mRNA, an XBP1 transcriptional target gene (Fig. 2B). In this case, the DNAJB9 mRNA was induced only about 1.5 fold, whereas in corresponding ER stress model the $D N A J B 9$ expression was higher (about 3-4 fold), suggesting that other transcriptional mechanisms may be responsible for this gene induction during UPR. The levels of XBP1s mRNA induction resulted in XBP1 protein levels (Fig. 2C) comparable to those observed after 6 hours of ER stress induced with 2.5 $\mu \mathrm{g} / \mathrm{ml} \mathrm{Tm}$ and about half of the protein levels observed with $50 \mathrm{nM} \mathrm{Tg}$ (Fig. 2E\&F), despite the fact that both of these stressors induced XBP1s mRNA comparably (Fig. 1C). The exogenous XBP1 signals were independent of IRE1 activity since $4 \mu 8 \mathrm{C}$, a specific IRE1 activity inhibitor, had no effect on the induced $X B P 1 s$ mRNA levels [54] (Fig. 2G). Furthermore, the XBP1 induction did not lead to accumulation of $X B P 1$ u mRNA (Fig. 2H). Notably, in the presence of doxycycline, the XBP1 protein was stably expressed up to a week (Fig. 2IJ), showing a trend to accumulate after a prolonged time of induction. And finally, the doxycycline used for the induction of XBP1s did not induce ER stress (Supplemental Fig. 1A) and siRNA knockdown of XBP1s mRNA induction with the inducible cell line dramatically reduced the XBP1s mRNA levels (Supplemental Fig. 1B).

In our analysis of XBP1-affected factors, we obtained RNA samples from the HeLa-XBP1s cell line under control conditions (no induction) and after $24 \mathrm{~h}$ of induction, and subjected both to RNA-seq analysis. Notably in these NGS analysis inductions of all $X B P 1$ isoform mRNAs were accessed as a one XBP1 gene change and in the range of 5 fold and that is reflected by about 2 log 2 fold change. The isoformdedicated analysis, however, indicated that the XBP1s mRNA induction was about $20 \mathrm{fold}$. In this analysis, we focused only on genes that were specifically affected by induction by at least a log fold (2 fold change) and had $P$ value below 0.05 .

We were aware that by applying such "loose" selection parameters, however, would result in a large group of genes. Given this concern, we performed independent validations of the XBP1 predicted targets. Furthermore, given the large number of identified genes fulfilling this criterion could also result from the doxycycline treatment. As a control, therefore, the RNA-seq data obtained from a comparable inducible HeLa cell line expressing low levels of XBP1U (HeLA-XBP1 $)$ was examined. These induced genes were omitted from further analysis. As previously mentioned, $X B P 1 s$ mRNA results from ER stress-activated IRE1 splicing of a $26 \mathrm{nt}$ unconventional intron in the coding region of unspliced XBP1 (XBP1u) that causes a frameshift. The XBP1 protein $(\sim 48 \mathrm{kDa})$ has the same N-terminus, but a longer and distinct Cterminus compared to the unspliced XBP1 protein $(\sim 29 \mathrm{kDa})[5,55]$. More importantly, the new Cterminus in XBP1 contains the transactivation domain $[5,55]$. The induction levels of XBP1 u mRNA in these cells were in the 10-fold range that did result in unspliced XBP1 protein expression (Fig. 3A-C) but did not result in XBP1s mRNA accumulation (Fig. 3D) or any increase in XBP1 transcriptional activity (Fig. 3E). The unspliced XBP1 protein levels are in agreement with previous reports that this protein is rapidly degraded [56]. Given this, the RNA-seq data obtained from the induced HeLA-XBP1 $u$ cell line were an appropriate control for our experiments.

The overlap of the RNA-seq data obtained from induced spliced XBP1 and unspliced XBP1 expression systems are illustrated in a Venn diagram in Fig. 4A. The functional assignment of XBP1 modulated 
genes was performed with Enrichr webserver using a strict criterion ( $P$ value $P<0.05$ and $q$ value $\mathrm{q}<$ 0.05). As shown in Fig. 4B, this analysis of expression profiles specific for cells expressing XBP1u did not revealed any specific activation of ER stress, UPR signaling or apoptotic pathways. Nevertheless, some of the unspliced XBP1-related expression changes could be assigned to cholesterol metabolism and the endosomal pathway. Furthermore, analysis of genes that were common between spliced and unspliced $X B P 1$ mRNA expression profiles did not result in any significant functional assignment. Notably, because of XBP1s induction, the mRNA of 345 and 199 genes were induced or reduced, respectively. Furthermore, this expression profile correlated well with changes related to the UPR that included protein folding, cellular proliferation, and negative regulation of apoptotic pathways (Fig. 4B).

Given that XBP1's impact on gene expression can result from both direct and indirect effects with transcription factors originating from the other UPR branches (PERK and ATF6), we decided to narrow our verification set to the genes that contained potential promoter regions for $X B P 1$. To verify the potential direct role of XBP1 during the UPR, the identified gene locations were analyzed for the presence of XBP1 binding motifs (Fig. 5A). Our analysis was in HeLa cells and we focused only on transcriptionally active chromatin regions.

This resulted in the selection of 58 genes potentially directly regulated by spliced XBP1 that were then validated in 3 independent biological replicates using 96 well qPCR arrays (Supplemental Table 2AB). The expression changes were accessed following XBP1 overexpression as well as silencing with specific siRNA against XBP1 during 6 hours of mild ER stress (induced with Tm or Tg). Furthermore, in our validation set we included HSPA5 (BIP) and DDIT3 (CHOP) mRNAs that were previously also reported to be regulated by XBP1 [57]. Interestingly, the $C H O P$ region did not contain any potential XBP1 binding motifs, whereas in BiPthere were 11 sites. This approach identified significant changes in 40 of the transcripts (Table 1).

As shown in Table 1 and Supplemental Table 2A, we observed that following XBP1s induction, 8 mRNAs were significantly induced that included ankyrin 2 (ANK2), glutathione-specific gammaglutamylcyclotransferase 1 (CHAC1), ER-Resident Protein ERdj4, DNAJB9, ER degradation enhancing alpha-mannosidase like protein 1 (EDEM1), ER lectin 1 (ERLEC1), forkhead box J2 (FOXJ2), SEC23B, and interferon-induced protein 53 (WARS). Notably, ERLEC1, WARS and SEC23B have been previously identified as XBP1-dependent genes in MCF-7 and HEK-293 cells [58, 59], whereas $C H A C 1$ has been identified recently as an important regulator of UPR-associated ferroptosis [60]. Furthermore, 5 mRNAs were significantly reduced upon XBP1s induction and included 1) IRE1 (ERN1), 2) growth arrest and DNA damage-inducible protein (GADD34) [61], a crucial PERK pathway regulator, 3) PUMA (BBC3), an important ER stress related proapoptotic factor [62]), 4) heat shock protein family $A$ (Hsp70) member $1 B$ (HSPA1B), and 5) heat shock protein family A (Hsp70) member 6 (HSPA6).

In the parallel $X B P 1$ silencing experiments (Table 1 and Supplemental Table 2B), we observed that mRNA levels of well-known XBP1 targets like DNAJB9 and $\operatorname{EDEM1}[43,57]$ as well as interleukin 6 - IL6 [63] that were significantly induced by both stressors and reduced upon XBP1 silencing. Also as previously 
reported, XBP1 silencing had a limited effect on HSPA5 (BiP) expression during ER stress [57]. Importantly, we also observed that $E R N 1, B B C 3$, and regulator of calcineurin 1 (RCAN1) were induced by both stressors and their levels were even higher after XBP1 silencing. Notably, we recently identified RCAN1 as an important pro-survival regulator of ER-stress induced cell fate decisions [21].

We also noted the induction of ER stress proapoptotic cyclin dependent kinase inhibitor 1A (CDKN1A (p21)) and cytoplasmic linker 2 (CLIP2) expression upon XBP1 silencing. Interestingly, CLIP2 has been associated as a key gene for diabetes mellitus development [64]. The PERK-dependent cyclin-dependent kinase 6 (CDK6 [65]) expression was significantly reduced only by $\mathrm{Tg}$ and its levels became even lower upon XBP1 silencing during both Tm and Tg treatments. ANK2, ATF3 and GADD45A mRNAs were induced by both stressors and their levels were further elevated upon $X B P 1$ silencing during Tg treatment. Notably, the UPR-induced proapoptotic GADD45A [21] has been proposed as an XBP1 dependent gene [57]. Furthermore, HSPA6 mRNA levels were significantly induced upon XBP1 silencing in Tm and Tg treated cells, but the expression of the HSPA6 gene was exceptionally low in HeLa cells, however, and therefore this observation will require further verification.

We also observed that $X B P 1$ silencing resulted in lower expression of the transcription factor involved in ER stress-related regulation of cell cycle progression early growth response 1 - EGR1 [66] in both stress models. Additionally, XBP1 silencing induced the anti-apoptotic dual specificity phosphatase 6 - DUSP6 gene [67] expression in Tm treated cells. Notably, DDIT3 (CHOP) and GADD34 levels were significantly induced in both ER stress models, and further increased upon XBP1 silencing in $\mathrm{Tg}$ treated cells whereas they were reduced in Tm treated cells (Fig. 5B). Furthermore, we did not find any significant correlation between the potential number of XBP1 binding motifs and their connection to actual functional effects. Importantly, the functional analysis of all these verified XBP1-related genes indicated that they were almost exclusively connected to ER stress outcomes including all 3 UPR branches and ERAD, and the regulation of apoptotic processes (Fig. 5C).

Despite some discrepancies between the data obtained from the $X B P 1$ induction and silencing in different ER stress models, we were able to define a group of genes whose expression was XBP1dependent and their expression was significantly affected in at least two out of three independent experimental approaches (XBP1 induction; silencing XBP1s during Tm treatment; or silencing XBP1s during $\mathrm{Tg}$ treatment) (Table 1). As shown in Fig. 5D, this resulted in final selection of a group of 17 genes. In this gene set, the expression of 6 genes (HSPA5, CDK6, DNAJB9, EDEM1, EGR1, SEC23B) was positively correlated with the XBP1 levels.

Notably, we also identified 3 genes, $B B C 3, E R N 1$ and $H S P A 6$, whose expression was negatively correlated with the XBP1 expression in both ER stress models. Given that $B B C 3$ encoded PUMA protein was reported as an important apoptotic factor during UPR, we also tested if XBP1-related reduction of $B B C 3 \mathrm{mRNA}$ levels were reflected by PUMA protein changes. As shown in Fig. 6A, in HeLa cells exposed to Tm $(2.5 \mu \mathrm{g} / \mathrm{ml})$, PUMA protein levels were negatively corelated with $X B P 1 s$ expression and further reduced after 8 hours when the XBP1 expression is maximal. Furthermore, when XBP1 is reduced after 16 hours 
of treatment, the PUMA levels rise. We also followed the consequences of XBP1s induction in HeLa cells exposed to Tm for 16 hours and observed that PUMA was significantly induced in the absence of XBP1s induction (Fig. 6BC). To test XBP1's impact on prosurvival UPR activity, we subjected HeLa cells to Tminduced ER stress for 16 hours and measured caspase 3/7 activity. We directly compared Tm-induced ER stress to Tm-induced stress in the presence of $X B P 1 s$ depletion with use of IRE1 inhibitor $(4 \mu 8 \mathrm{C})$

(Fig. 6D). We found that impairing IRE1 activity accelerates cell death in ER stressed cells, whereas XBP1 expression correlated with a clear prosurvival effect (Fig. 6D). Finally, since PUMA was reported to stimulate the intrinsic pathway of apoptosis $[68,69]$, we performed an analogous experiment and siRNA silenced PUMA (Fig. 6E). Interestingly, we did not observe any significant changes in caspase $3 / 7$ activity related to PUMA depletion (Fig. 6E).

In summary, we identified 8 genes whose expression was ER stress model-dependent and/or not affected by XBP1 induction alone: DUSP6, DDIT3, GADD34, RCAN1, ICAM1, DNAJB2, CLIP2 and CDKN1A. This set contains mainly genes that can be attributed to the PERK pathway activity (DDIT3, GADD34) and cell survival (DDIT3, GADD34, RCAN1 and CDK1A), suggesting that their levels result from both XBP1 activity and other UPR pathways, including the PERK pathway.

\section{Discussion}

The IRE1-dependent pathway is the most antient and conserved branch of UPR [24] and serves as the molecular timer and executor for ER stress-related cell death [70-72]. It is therefore not surprising that the role of its downstream transcription factor, XBP1, has been extensively studied [43, 51, 57-59, 73, 74]. The transcriptional targets of XBP1 are well identified and consist of ERAD components (EDEM1), chaperones (HSPA5, DNAJB9, DNAJC3), and vesicle trafficking components (SEC23B) [57-59, 73]. Furthermore, genes involved in the inflammatory responses (including IL6) [59], as well as genes not related to UPR pathways including adipocyte and myogenic differentiation (C/EBP and MIST1) have been proposed as tissue-dependent XBP1 transcriptional targets [75]. Consequently, the XBP1 has been widely accepted as an adaptive component of UPR that is responsible for facilitating protein folding and ER expansion.

Despite these advances, determining the global network of XBP1 transcriptional activity and its consequences on cell fate decisions remains less clear. Part of the problem in defining XBP1's role involves analyzing its function in models that are often based on one type of ER stressor or are utilizing high levels of overexpression of XBP1. Furthermore, the studies often focus on a small subset of induced genes. In our approach, we exploited inducible cell lines capable of XBP1(s) and XBP1(u) lower expression levels and two models of pharmacological ER stress induction, glycosylation inhibition and disruption of ER calcium homeostasis. Using this system, we were able to demonstrate the induction of the main UPR mediators including HSPA5 (BIP), IRE1, XBP1s and CHOP. Notably, the levels of XBP1s mRNA obtained during cell line induction were on the low end of those observed in our ER stress models. 
To follow the XBP1-related changes in transcriptome, we performed next generation sequencing profiling in HeLa cells with the induced expression of XBP1s or XBP1 $u$ and focused on changes in gene expression related mainly to prosurvival and apoptotic UPR signaling pathways. Notably XBP1u expression did not result in any changes in which we could clearly assign to these activities. The unspliced XBP1 protein has been shown to be rapidly degraded and maintained at low levels and the $X B P 14$ transgene transcript could not be processed to functional XBP1, and our results are in good agreement with previous reports [56].

Nevertheless, the $X B P 1 s$ transgene induction resulted in wide changes of expression profiles of the genes involved in the UPR including DNAJB9 and EDEM1, stress responses, and regulation of cellular biosynthetic and apoptotic responses (Fig. 4). The results confirmed XBP1's role as a crucial UPR mediator and potentially defined a large set of genes which resulted from XBP1 transcriptional activity. Importantly, following XBP1s induction, we did not observe the some of the classical UPR activation genes since both $B I P$ and $C H O P$ mRNA levels remained relatively constant, and therefore it is quite plausible that the observed transcriptomic changes often seen did not result specifically from XBP1 activity.

To further test this hypothesis, we selected a set of 58 genes (Supplemental Table 2) whose genomic locations were in the proximity of XBP1 binding motifs and DDIT3 and HSPA5 and validated them independently. The results revealed XBP1-related changes in 40 transcripts, most of which were related to the UPR stress responses and regulation of apoptosis (Fig. 5). The number of potential XBP1 binding motifs in the promoter regions of genes did not correlate well with their transcript expression levels, suggesting that other requirements such as the relative position from the transcriptional start site or the presence of other potential binding motifs (such as ATF6 for example $[57,59]$ ) may be necessary to achieve efficient transcription. However, the effects of the of number of transcription factor binding motifs on expression are only observed for some transcription factors [76]. Nevertheless, homotypic clusters of motifs for some transcription factors are known to potentiate the effects of these factors on expression for some genes [77]. Therefore, we also tested our gene set for a correlation between XBP1 motif clusters and fold changes, but no significant effects were observed. Finally, taking into account extreme complexity and dynamic course of UPR signaling, it is important to note that XBP1 cooperates with the other arms of UPR to modulate of transcriptomic profiles, rather than being a master regulator of gene expression. Nevertheless, most of the preselected genes displayed expression patterns that positively correlated the elevated expression levels of XBP1.

Despite our best efforts to find the optimal mild ER stress conditions, Tm and Tg still have different impact on the course of UPR signaling pathways, and the Tm-treated cells were more prone to apoptosis (Fig. 1). Hence, we believe that these differences between $\mathrm{Tm}$ and $\mathrm{Tg}$ could result in discrepancies in expression profiles of the cell fate decisions and PERK-induced genes including DDIT3, GADD34, ATF3 and RCAN1. In general, silencing XBP1s during Tg treatment resulted in higher expression of DDIT3, GADD34, ATF3 and RCAN1, whereas a complete lack of XBP1 during Tm treatment resulted in reduced expression of these genes. Since, all these transcripts are closely related to the PERK branch of UPR, there 
is a possibility of XBP1-mediated crosstalk between this pathway and the IRE1 branch that determines cell fate decisions. Our results suggest that the gene expression modulations by XBP1 can also be influenced by other UPR pathways. However, this hypothesis and the related mechanisms will obviously require further study.

Despite the differences between the data obtained from the XBP1 induction and silencing in different ER stress models, we were able to define a group of genes whose expression was clearly XBP1 dependent (Fig. 5C). The expression of HSPA5, CDK6, DNAJB9, EDEM1, EGR1, SEC23B was clearly positively correlated with the XBP1 levels. In all of these genes, their expression was not only induced along with $X B P 1 s$ induction, but it was also reduced when XBP1 was silenced in both stress models. However, HSPA5, EGR 1 and $C D K 6$ only correlate positively in our ER stress induced conditions and not in an XBP1 overexpression model, suggesting that ATF6 may also be required for their expression induction $[57,59]$.

Here we have identified the 3 genes, BBC3 (PUMA), ERN1 (IRE1) and HSPA6 (BiP), whose expression was clearly negatively correlated with the XBP1 and their levels were reduced upon $X B P 1$ induction and induced upon XBP1 silencing in both stress models. In the case of HSPA6, the expression levels in HeLa cells were extremely low and therefore may represent a cell-type specific effect. The expression levels for the $B B C 3$ and $E R N 1$, however, were more robust and clearly indicated this reversal effect during siRNA silencing of XBP1s. Obviously, both BBC3 (PUMA) and ERN1 (IRE1) are crucial UPR regulators, and their

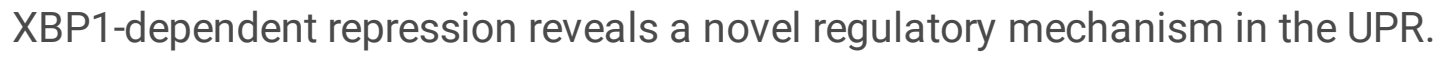

The ability of XBP1 to attenuate ERN1 expression and thus reduce IRE1 activity identifies novel negative feedback regulatory loop between XBP1 and IRE1. Although this observation and potential consequences of such a regulation requires further verification, it is clear that other UPR branches have negative effects on IRE1 activity that include PERK [72] and ATF6 [78]. Nevertheless, the implications of this during ER stress is that XBP1 controls its own levels and cell fate by limiting IRE1 activity.

Furthermore, numerous reports proposed that PUMA as an important and PERK-related contributor to UPR-related cell death [79-81], since it can inhibit all prosurvival Blc-2 family members and activate the intrinsic pathway of apoptosis $[68,69]$. Hence, it is plausible that by preventing $B B C 3$ (PUMA) accumulation, XBP1 modulates the extent of intrinsic apoptotic signaling and thus contributes to the adaptive UPR response. Although our data clearly show that XBP1s induction leads to a reduction of PUMA protein levels, and at the same time reduces the extend of apoptotic UPR signaling (Fig. 6), evaluating the exact contribution of XBP1's role will require further study.

Taken together, our approach not only confirmed previously known XBP1 roles during the UPR, but also identified novel targets of this transcription factor that regulate the mechanisms of the UPR cell fate decisions. Having said that, our experimental approaches are limited by the complexity of UPR signaling pathways and all the other factors involved in this process and therefore further studies will be necessary to understand the complex relationships between XBP1 and all of its targets. One of the limitations here is that the time (at least 24 hours) required to obtain sufficient XBP1 expression prevents the model from 
reproducing the acute stress response since IRE-1 is transiently activated and rapidly downregulated by the PERK arm of the stress response [71].

In summary, the studies presented here have identified that XBP1 can repress expression of two key players involved in UPR, IRE1 and PUMA, and further studies are obviously required to decipher the molecular mechanisms underlying this observation.

\section{Abbreviations}

ACLY - ATP Citrate Lyase; ANK2 - ankyrin 2; ATF3 - activating transcription factor 3; ATF6 - activating transcription factor 6; $B B C 3$ - BCL2 Binding Component 3; BiP - binding immunoglobulin protein (glucoseregulated protein 78, a.k.a. HSPA5); BSA - bovine serum albumin; CALR - Calreticulin; CDK6 - cyclin dependent kinase 6; CDKN1A - cyclin dependent kinase inhibitor 1A (aka p21); CEBPB - CCAAT Enhancer Binding Protein Beta (aka C/EBP); CHAC1 - ChaC glutathione specific gamma-glutamylcyclotransferase 1; CHOP - CCAAT-enhancer-binding protein homologous protein (a.k.a DDIT3); CLIP2 - cytoplasmic linker 2; CTRL - control; DDIT3 - DNA damage inducible transcript 3 (aka CHOP); DHCR24 - 24-dehydrocholesterol reductase; DMSO - dimethyl sulfoxide; DNAJA1 - DnaJ heat shock protein family (Hsp40) member A1; DNAJB2 - DnaJ heat shock protein family (Hsp40) member B2; DNAJB9 - DnaJ heat shock protein family (Hsp40) member B9 aka (aka ERdj4); DNAJC3 - DnaJ heat shock protein family (Hsp40) member C3; DSP - Desmoplakin; DUSP6 - dual specificity phosphatase 6; ECL - Enhanced chemiluminescence; EDEM1 - ER degradation enhancing alpha-mannosidase like protein 1; EGR1 - early growth response 1; elF2a eukaryotic translation initiation factor 2a; ER - endoplasmic reticulum; ERAD - endoplasmic reticulum associated degradation; ERLEC1 - ER lectin 1; ERN1 - endoplasmic reticulum to nucleus signaling 1 (a.k.a. IRE1); FOXJ2 - forkhead box J2; GADD34 Growth Arrest And DNA Damage-Inducible Protein (aka PPP1R15A); GADD45A - growth arrest and DNA damage inducible alpha; GADD45B - growth arrest and DNA damage inducible beta; GAPDH - Glyceraldehyde 3-phosphate dehydrogenase; GEO - gene expression omnibus; HEK293 cells are Human Embryonic Kidney cells; HeLa - Human cervix adenocarcinoma cells; HSPA1B - heat shock protein family A (Hsp70) member 1B; HSPA5 - heat shock protein family a (Hsp70) member 5, (a.k.a. BIP); HSPA6 - heat shock protein family a (Hsp70) member 6; HSPA8 - heat shock protein family A (Hsp70) member 8; HUVECs - human primary endothelial cells; ICAM1-intercellular adhesion molecule 1; IL $1 A$ - interleukin 1a; IL6 -interleukin 6; IRE1 - inositol-requiring protein 1; MAP3K7 - C-Terminal Like; MCF-7 - human breast cancer cell line; MIST1-Basic Helix-Loop-Helix Family Member A15; NFKB2- nuclear Factor Kappa B Subunit 2; NGS - next generation sequencing; PBS phosphate-bufferedsaline; PERK - protein kinase RNA-like ER kinase; PUMA - BCL2 binding component 3 (a.k.a. BBC3); qPCR - quantitative polymerase chain reaction; qRT-PCR - quantitative real-time PCR; R.L.U. relative light units; RCAN1 - regulator of calcineurin 1; RPLPO - neutral ribosomal phosphoprotein P0; RTCA - real-time cell analysis; SD - standard deviations; SEC23B and interferon-induced protein 53; SERCA - sarco/endoplasmic reticulum Ca2+ATPase; siRNA - small interfering RNA; SNA/1 - snail family transcriptional repressor 1; Tg - thapsigargin; Tm - tunicamycin; UPR - unfolded protein response; WARS Tryptophanyl-tRNA Synthetase; $X B P 1$ - $\mathrm{x}$-box binding protein $1 ; X B P 1 s$ - spliced $\mathrm{x}$-box binding protein 1 ; $X B P 14$ - unspliced form of XBP1; ZNF432- zinc finger protein 432. 


\section{Declarations}

Funding: This research was funded by National Science Center "OPUS" Program under contract

UMO-2020/37/B/NZ3/00861 to RB, J.F.C. was funded by an NIH P30 DK072482 and a Research Development Program Grant from the Cystic Fibrosis Foundation.

Data availability: Deep sequencing data were deposited in Gene Expression Omnibus (GEO) at accession number: GSE160416

Acknowledgments: We would like to thank Anna Janszak-Jasiecka and Marcin Serocki for their kind assistance.

Conflicts of Interest: The authors declare no conflict of interest. The funders had no role in the design of the study; in the collection, analyses, or interpretation of data or in the writing of the manuscript or in the decision to publish the results.

Author Contributions: Conceived and designed the experiments: R.B. Performed the experiments: M.G.; A.S.; S.B.; Analyzed the data: R.B.; J.F.C.; A.C. J.K.; D.K.C and P.M. M.D. Contributed reagents/materials/resources: R.B.; Wrote the paper: R.B. and J.F.C. All authors read the final version of the manuscript.

\section{References}

1. Berridge, M. J. (2002) The endoplasmic reticulum: a multifunctional signaling organelle. Cell Calcium. 32, 235-249

2. Urra, H., Dufey, E., Lisbona, F., Rojas-Rivera, D. and Hetz, C. (2013) When ER stress reaches a dead end. Biochimica et biophysica acta. 1833, 3507-3517

3. Schroder, M. and Kaufman, R. J. (2005) ER stress and the unfolded protein response. Mutation research. 569, 29-63

4. Sano, R. and Reed, J. C. (2013) ER stress-induced cell death mechanisms. Biochimica et biophysica acta. $1833,3460-3470$

5. Yoshida, H., Matsui, T., Yamamoto, A., Okada, T. and Mori, K. (2001) XBP1 mRNA is induced by ATF6 and spliced by IRE1 in response to ER stress to produce a highly active transcription factor. Cell. 107, 881891

6. Back, S. H., Lee, K., Vink, E. and Kaufman, R. J. (2006) Cytoplasmic IRE1alpha-mediated XBP1 mRNA splicing in the absence of nuclear processing and endoplasmic reticulum stress. J Biol Chem. 281, 18691-18706 
7. Lee, K., Tirasophon, W., Shen, X., Michalak, M., Prywes, R., Okada, T., Yoshida, H., Mori, K. and Kaufman, R. J. (2002) IRE1-mediated unconventional mRNA splicing and S2P-mediated ATF6 cleavage merge to regulate XBP1 in signaling the unfolded protein response. Genes \& development. 16, 452-466

8. Uemura, A., Oku, M., Mori, K. and Yoshida, H. (2009) Unconventional splicing of XBP1 mRNA occurs in the cytoplasm during the mammalian unfolded protein response. J Cell Sci. 122, 2877-2886

9. Schroder, M. and Kaufman, R. J. (2005) The mammalian unfolded protein response. Annual review of biochemistry. 74, 739-789

10. Karagoz, G. E., Acosta-Alvear, D. and Walter, P. (2019) The Unfolded Protein Response: Detecting and Responding to Fluctuations in the Protein-Folding Capacity of the Endoplasmic Reticulum. Cold Spring Harb Perspect Biol. 11

11. Oyadomari, S. and Mori, M. (2004) Roles of CHOP/GADD153 in endoplasmic reticulum stress. Cell Death Differ. 11, 381-389

12. Urano, F., Wang, X., Bertolotti, A., Zhang, Y., Chung, P., Harding, H. P. and Ron, D. (2000) Coupling of stress in the ER to activation of JNK protein kinases by transmembrane protein kinase IRE1. Science. 287, 664-666

13. Hitomi, J., Katayama, T., Eguchi, Y., Kudo, T., Taniguchi, M., Koyama, Y., Manabe, T., Yamagishi, S., Bando, Y., Imaizumi, K., Tsujimoto, Y. and Tohyama, M. (2004) Involvement of caspase-4 in endoplasmic reticulum stress-induced apoptosis and Abeta-induced cell death. J Cell Biol. 165, 347-356

14. Li, J., Lee, B. and Lee, A. S. (2006) Endoplasmic reticulum stress-induced apoptosis: multiple pathways and activation of p53-up-regulated modulator of apoptosis (PUMA) and NOXA by p53. J Biol Chem. 281, 7260-7270

15. Lam, M., Marsters, S. A., Ashkenazi, A. and Walter, P. (2020) Misfolded proteins bind and activate death receptor 5 to trigger apoptosis during unresolved endoplasmic reticulum stress. Elife. $\mathbf{9}$

16. Lu, M., Lawrence, D. A., Marsters, S., Acosta-Alvear, D., Kimmig, P., Mendez, A. S., Paton, A. W., Paton, J. C., Walter, P. and Ashkenazi, A. (2014) Opposing unfolded-protein-response signals converge on death receptor 5 to control apoptosis. Science. $\mathbf{3 4 5}, 98-101$

17. Wang, S. and Kaufman, R. J. (2012) The impact of the unfolded protein response on human disease. J Cell Biol. 197, 857-867

18. Hetz, C. (2012) The unfolded protein response: controlling cell fate decisions under ER stress and beyond. Nat Rev Mol Cell Bio. 13, 89-102

19. Hetz, C., Chevet, E. and Oakes, S. A. (2015) Proteostasis control by the unfolded protein response. Nature cell biology. 17, 829-838 
20. Shore, G. C., Papa, F. R. and Oakes, S. A. (2011) Signaling cell death from the endoplasmic reticulum stress response. Curr Opin Cell Biol. 23, 143-149

21. Gebert, M., Jaskiewicz, M., Moszynska, A., Collawn, J. F. and Bartoszewski, R. (2020) The Effects of Single Nucleotide Polymorphisms in Cancer RNAi Therapies. Cancers (Basel). 12

22. Rutkowski, D. T., Arnold, S. M., Miller, C. N., Wu, J., Li, J., Gunnison, K. M., Mori, K., Sadighi Akha, A. A., Raden, D. and Kaufman, R. J. (2006) Adaptation to ER stress is mediated by differential stabilities of prosurvival and pro-apoptotic mRNAs and proteins. Plos Biol. 4, e374

23. Karam, R., Lou, C. H., Kroeger, H., Huang, L., Lin, J. H. and Wilkinson, M. F. (2015) The unfolded protein response is shaped by the NMD pathway. Embo Rep. 16, 599-609

24. Zhang, L., Zhang, C. and Wang, A. (2016) Divergence and Conservation of the Major UPR Branch IRE1bZIP Signaling Pathway across Eukaryotes. Sci Rep. 6, 27362

25. Chen, H. and Qi, L. (2010) SUMO modification regulates the transcriptional activity of XBP1. The Biochemical journal. 429, 95-102

26. Lee, J., Sun, C., Zhou, Y., Lee, J., Gokalp, D., Herrema, H., Park, S. W., Davis, R. J. and Ozcan, U. (2011) p38 MAPK-mediated regulation of Xbp1s is crucial for glucose homeostasis. Nature medicine. 17, 12511260

27. Wang, F. M., Chen, Y. J. and Ouyang, H. J. (2011) Regulation of unfolded protein response modulator XBP1s by acetylation and deacetylation. The Biochemical journal. 433, 245-252

28. Yanagitani, K., Kimata, Y., Kadokura, H. and Kohno, K. (2011) Translational pausing ensures membrane targeting and cytoplasmic splicing of XBP1u mRNA. Science. 331, 586-589

29. Majumder, M., Huang, C., Snider, M. D., Komar, A. A., Tanaka, J., Kaufman, R. J., Krokowski, D. and Hatzoglou, M. (2012) A novel feedback loop regulates the response to endoplasmic reticulum stress via the cooperation of cytoplasmic splicing and mRNA translation. Molecular and cellular biology. 32, 9921003

30. Barger, C. J., Branick, C., Chee, L. and Karpf, A. R. (2019) Pan-Cancer Analyses Reveal Genomic Features of FOXM1 Overexpression in Cancer. Cancers (Basel). 11

31. Malashicheva, A., Kanzler, B., Tolkunova, E., Trono, D. and Tomilin, A. (2007) Lentivirus as a tool for lineage-specific gene manipulations (vol 45, pg 456, 2007). Genesis. 45, 793-793

32. Gomez-Martinez, M., Schmitz, D. and Hergovich, A. (2013) Generation of stable human cell lines with Tetracycline-inducible (Tet-on) shRNA or cDNA expression. Jove-J Vis Exp, e50171 
33. Bartoszewska, S., Kroliczewski, J., Crossman, D. K., Pogorzelska, A., Baginski, M., Collawn, J. F. and Bartoszewski, R. (2021) Triazoloacridone C-1305 impairs XBP1 splicing by acting as a potential IRE1alpha endoribonuclease inhibitor. Cell Mol Biol Lett. 26, 11

34. Gebert, M., Bartoszewska, S., Janaszak-Jasiecka, A., Moszynska, A., Cabaj, A., Kroliczewski, J., Madanecki, P., Ochocka, R. J., Crossman, D. K., Collawn, J. F. and Bartoszewski, R. (2018) PIWI proteins contribute to apoptosis during the UPR in human airway epithelial cells. Sci Rep. 8, 16431

35. Lamkanfi, M. and Kanneganti, T. D. (2010) Caspase-7: a protease involved in apoptosis and inflammation. Int J Biochem Cell B. 42, 21-24

36. Dobin, A., Davis, C. A., Schlesinger, F., Drenkow, J., Zaleski, C., Jha, S., Batut, P., Chaisson, M. and Gingeras, T. R. (2013) STAR: ultrafast universal RNA-seq aligner. Bioinformatics. 29, 15-21

37. Trapnell, C., Williams, B. A., Pertea, G., Mortazavi, A., Kwan, G., van Baren, M. J., Salzberg, S. L., Wold, B. J. and Pachter, L. (2010) Transcript assembly and quantification by RNA-Seq reveals unannotated transcripts and isoform switching during cell differentiation. Nat Biotechnol. 28, 511-515

38. Kuleshov, M. V., Jones, M. R., Rouillard, A. D., Fernandez, N. F., Duan, Q., Wang, Z., Koplev, S., Jenkins, S. L., Jagodnik, K. M., Lachmann, A., McDermott, M. G., Monteiro, C. D., Gundersen, G. W. and Ma'ayan, A. (2016) Enrichr: a comprehensive gene set enrichment analysis web server 2016 update. Nucleic Acids Res. 44, W90-97

39. Bartoszewska, S., Kamysz, W., Jakiela, B., Sanak, M., Kroliczewski, J., Bebok, Z., Bartoszewski, R. and Collawn, J. F. (2017) miR-200b downregulates CFTR during hypoxia in human lung epithelial cells. Cell Mol Biol Lett. 22, 23

40. Moszynska, A., Collawn, J. F. and Bartoszewski, R. (2020) IRE1 Endoribonuclease Activity Modulates Hypoxic HIF-1alpha Signaling in Human Endothelial Cells. Biomolecules. 10

41. Bartoszewski, R., Serocki, M., Janaszak-Jasiecka, A., Bartoszewska, S., Kochan-Jamrozy, K., Piotrowski, A., Króliczewski, J. and Collawn, J. F. (2017) miR-200b downregulates Kruppel Like Factor 2 (KLF2) during acute hypoxia in human endothelial cells. European Journal of Cell Biology. 96, 758-766

42. Livak, K. J. and Schmittgen, T. D. (2001) Analysis of relative gene expression data using real-time quantitative PCR and the 2(-Delta Delta C(T)) Method. Methods (San Diego, Calif.). 25, 402-408

43. Bartoszewska, S., Cabaj, A., Dabrowski, M., Collawn, J. F. and Bartoszewski, R. (2019) miR-34c-5p modulates X-box-binding protein 1 (XBP1) expression during the adaptive phase of the unfolded protein response. FASEB J. 33, 11541-11554

44. Kulakovskiy, I. V., Medvedeva, Y. A., Schaefer, U., Kasianov, A. S., Vorontsov, I. E., Bajic, V. B. and Makeev, V. J. (2013) HOCOMOCO: a comprehensive collection of human transcription factor binding sites models. Nucleic Acids Res. 41, D195-202 
45. Chen, X., Iliopoulos, D., Zhang, Q., Tang, Q., Greenblatt, M. B., Hatziapostolou, M., Lim, E., Tam, W. L., Ni, M., Chen, Y., Mai, J., Shen, H., Hu, D. Z., Adoro, S., Hu, B., Song, M., Tan, C., Landis, M. D., Ferrari, M., Shin, S. J., Brown, M., Chang, J. C., Liu, X. S. and Glimcher, L. H. (2014) XBP1 promotes triple-negative breast cancer by controlling the HIF1alpha pathway. Nature. 508, 103-107

46. Turatsinze, J. V., Thomas-Chollier, M., Defrance, M. and van Helden, J. (2008) Using RSAT to scan genome sequences for transcription factor binding sites and cis-regulatory modules. Nat Protoc. 3, 15781588

47. Consortium, E. P. (2012) An integrated encyclopedia of DNA elements in the human genome. Nature. 489, 57-74

48. Zerbino, D. R., Achuthan, P., Akanni, W., Amode, M. R., Barrell, D., Bhai, J., Billis, K., Cummins, C., Gall, A., Giron, C. G., Gil, L., Gordon, L., Haggerty, L., Haskell, E., Hourlier, T., Izuogu, O. G., Janacek, S. H., Juettemann, T., To, J. K., Laird, M. R., Lavidas, I., Liu, Z., Loveland, J. E., Maurel, T., McLaren, W., Moore, B., Mudge, J., Murphy, D. N., Newman, V., Nuhn, M., Ogeh, D., Ong, C. K., Parker, A., Patricio, M., Riat, H. S., Schuilenburg, H., Sheppard, D., Sparrow, H., Taylor, K., Thormann, A., Vullo, A., Walts, B., Zadissa, A., Frankish, A., Hunt, S. E., Kostadima, M., Langridge, N., Martin, F. J., Muffato, M., Perry, E., Ruffier, M., Staines, D. M., Trevanion, S. J., Aken, B. L., Cunningham, F., Yates, A. and Flicek, P. (2018) Ensembl 2018. Nucleic Acids Res. 46, D754-D761

49. Krystkowiak, I., Lenart, J., Debski, K., Kuterba, P., Petas, M., Kaminska, B. and Dabrowski, M. (2013) Nencki Genomics Database-Ensembl funcgen enhanced with intersections, user data and genome-wide TFBS motifs. Database : the journal of biological databases and curation. 2013, bat069

50. Li, J., Ni, M., Lee, B., Barron, E., Hinton, D. R. and Lee, A. S. (2008) The unfolded protein response regulator GRP78/BiP is required for endoplasmic reticulum integrity and stress-induced autophagy in mammalian cells. Cell Death Differ. 15, 1460-1471

51. Bartoszewski, R., Brewer, J. W., Rab, A., Crossman, D. K., Bartoszewska, S., Kapoor, N., Fuller, C., Collawn, J. F. and Bebok, Z. (2011) The unfolded protein response (UPR)-activated transcription factor Xbox-binding protein 1 (XBP1) induces microRNA-346 expression that targets the human antigen peptide transporter 1 (TAP1) mRNA and governs immune regulatory genes. J Biol Chem. 286, 41862-41870

52. Shen, J., Chen, X., Hendershot, L. and Prywes, R. (2002) ER stress regulation of ATF6 localization by dissociation of BiP/GRP78 binding and unmasking of Golgi localization signals. Dev Cell. 3, 99-111

53. Iurlaro, R. and Munoz-Pinedo, C. (2016) Cell death induced by endoplasmic reticulum stress. Febs J. 283, 2640-2652

54. Cross, B. C., Bond, P. J., Sadowski, P. G., Jha, B. K., Zak, J., Goodman, J. M., Silverman, R. H., Neubert, T. A., Baxendale, I. R., Ron, D. and Harding, H. P. (2012) The molecular basis for selective inhibition of 
unconventional mRNA splicing by an IRE1-binding small molecule. Proc Natl Acad Sci U S A. 109, E869878

55. Grimson, A., Farh, K. K., Johnston, W. K., Garrett-Engele, P., Lim, L. P. and Bartel, D. P. (2007) MicroRNA targeting specificity in mammals: determinants beyond seed pairing. Mol Cell. 27, 91-105

56. Tirosh, B., Iwakoshi, N. N., Glimcher, L. H. and Ploegh, H. L. (2006) Rapid turnover of unspliced Xbp-1 as a factor that modulates the unfolded protein response. J Biol Chem. 281, 5852-5860

57. Lee, A. H., Iwakoshi, N. N. and Glimcher, L. H. (2003) XBP-1 regulates a subset of endoplasmic reticulum resident chaperone genes in the unfolded protein response. Molecular and cellular biology. $\mathbf{2 3}$, 7448-7459

58. Misiewicz, M., Dery, M. A., Foveau, B., Jodoin, J., Ruths, D. and LeBlanc, A. C. (2013) Identification of a novel endoplasmic reticulum stress response element regulated by XBP1. J Biol Chem. 288, 20378-20391

59. Shaffer, A. L., Shapiro-Shelef, M., Iwakoshi, N. N., Lee, A. H., Qian, S. B., Zhao, H., Yu, X., Yang, L., Tan, B. K., Rosenwald, A., Hurt, E. M., Petroulakis, E., Sonenberg, N., Yewdell, J. W., Calame, K., Glimcher, L. H. and Staudt, L. M. (2004) XBP1, downstream of Blimp-1, expands the secretory apparatus and other organelles, and increases protein synthesis in plasma cell differentiation. Immunity. 21, 81-93

60. Gaudette, B. T., Jones, D. D., Bortnick, A., Argon, Y. and Allman, D. (2020) mTORC1 coordinates an immediate unfolded protein response-related transcriptome in activated $B$ cells preceding antibody secretion. Nat Commun. 11, 723

61. Brush, M. H., Weiser, D. C. and Shenolikar, S. (2003) Growth arrest and DNA damage-inducible protein GADD34 targets protein phosphatase 1 alpha to the endoplasmic reticulum and promotes dephosphorylation of the alpha subunit of eukaryotic translation initiation factor 2 . Molecular and cellular biology. 23, 1292-1303

62. Gupta, S., Giricz, Z., Natoni, A., Donnelly, N., Deegan, S., Szegezdi, E. and Samali, A. (2012) NOXA contributes to the sensitivity of PERK-deficient cells to ER stress. Febs Lett. 586, 4023-4030

63. Fang, P., Xiang, L., Huang, S., Jin, L., Zhou, G., Zhuge, L., Li, J., Fan, H., Zhou, L., Pan, C. and Zheng, Y. (2018) IRE1alpha-XBP1 signaling pathway regulates IL-6 expression and promotes progression of hepatocellular carcinoma. Oncol Lett. 16, 4729-4736

64. Liu, G. M., Zeng, H. D., Zhang, C. Y. and Xu, J. W. (2019) Key genes associated with diabetes mellitus and hepatocellular carcinoma. Pathol Res Pract. 215, 152510

65. Brewer, J. W. and Diehl, J. A. (2000) PERK mediates cell-cycle exit during the mammalian unfolded protein response. Proc Natl Acad Sci U S A. 97, 12625-12630 
66. Shan, J., Dudenhausen, E. and Kilberg, M. S. (2019) Induction of early growth response gene 1 (EGR1) by endoplasmic reticulum stress is mediated by the extracellular regulated kinase (ERK) arm of the MAPK pathways. Biochim Biophys Acta Mol Cell Res. 1866, 371-381

67. Piya, S., Kim, J. Y., Bae, J., Seol, D. W., Moon, A. R. and Kim, T. H. (2012) DUSP6 is a novel transcriptional target of $\mathrm{p} 53$ and regulates p53-mediated apoptosis by modulating expression levels of Bcl-2 family proteins. Febs Lett. 586, 4233-4240

68. Willis, S. N., Fletcher, J. I., Kaufmann, T., van Delft, M. F., Chen, L., Czabotar, P. E., lerino, H., Lee, E. F., Fairlie, W. D., Bouillet, P., Strasser, A., Kluck, R. M., Adams, J. M. and Huang, D. C. (2007) Apoptosis initiated when $\mathrm{BH} 3$ ligands engage multiple Bcl-2 homologs, not Bax or Bak. Science. 315, 856-859

69. Gurzov, E. N., Germano, C. M., Cunha, D. A., Ortis, F., Vanderwinden, J. M., Marchetti, P., Zhang, L. and Eizirik, D. L. (2010) p53 up-regulated modulator of apoptosis (PUMA) activation contributes to pancreatic beta-cell apoptosis induced by proinflammatory cytokines and endoplasmic reticulum stress. J Biol Chem. 285, 19910-19920

70. Chen, Y. and Brandizzi, F. (2013) IRE1: ER stress sensor and cell fate executor. Trends Cell Biol. 23, 547-555

71. Shemorry, A., Harnoss, J. M., Guttman, O., Marsters, S. A., Komuves, L. G., Lawrence, D. A. and Ashkenazi, A. (2019) Caspase-mediated cleavage of IRE1 controls apoptotic cell commitment during endoplasmic reticulum stress. Elife. 8, e47084

72. Chang, T. K., Lawrence, D. A., Lu, M., Tan, J., Harnoss, J. M., Marsters, S. A., Liu, P., Sandoval, W., Martin, S. E. and Ashkenazi, A. (2018) Coordination between Two Branches of the Unfolded Protein Response Determines Apoptotic Cell Fate. Molecular cell. 71, 629-636.e625

73. Byrd, A. E. and Brewer, J. W. (2012) Intricately Regulated: A Cellular Toolbox for Fine-Tuning XBP1 Expression and Activity. Cells. 1, 738-753

74. Bartoszewski, R., Rab, A., Jurkuvenaite, A., Mazur, M., Wakefield, J., Collawn, J. F. and Bebok, Z. (2008) Activation of the unfolded protein response by deltaF508 CFTR. Am J Respir Cell Mol Biol. 39, 448-457

75. He, Y., Sun, S., Sha, H., Liu, Z., Yang, L., Xue, Z., Chen, H. and Qi, L. (2010) Emerging roles for XBP1, a sUPeR transcription factor. Gene Expression. 15, 13-25

76. Weingarten-Gabbay, S., Nir, R., Lubliner, S., Sharon, E., Kalma, Y., Weinberger, A. and Segal, E. (2019) Systematic interrogation of human promoters. Genome Res. 29, 171-183

77. Lavallee, J. F., Gray, T. A., Dumville, J., Russell, W. and Cullum, N. (2017) The effects of care bundles on patient outcomes: a systematic review and meta-analysis. Implement Sci. 12, 142 
78. Walter, F., O'Brien, A., Concannon, C. G., Düssmann, H. and Prehn, J. H. M. (2018) ER stress signaling has an activating transcription factor 6a (ATF6)-dependent "off-switch". J Biol Chem. 293, 18270-18284

79. Wali, J. A., Rondas, D., McKenzie, M. D., Zhao, Y., Elkerbout, L., Fynch, S., Gurzov, E. N., Akira, S., Mathieu, C., Kay, T. W. H., Overbergh, L., Strasser, A. and Thomas, H. E. (2014) The proapoptotic BH3-only proteins Bim and Puma are downstream of endoplasmic reticulum and mitochondrial oxidative stress in pancreatic islets in response to glucotoxicity. Cell Death \& Disease. 5, e1124-e1124

80. Szegezdi, E., Logue, S. E., Gorman, A. M. and Samali, A. (2006) Mediators of endoplasmic reticulum stress-induced apoptosis. EMBO Rep. 7, 880-885

81. Pagliarini, V., Giglio, P., Bernardoni, P., De Zio, D., Fimia, G. M., Piacentini, M. and Corazzari, M. (2015) Downregulation of E2F1 during ER stress is required to induce apoptosis. Journal of Cell Science. 128, 1166-1179

82. Heberle, H., Meirelles, G. V., da Silva, F. R., Telles, G. P. and Minghim, R. (2015) InteractiVenn: a webbased tool for the analysis of sets through Venn diagrams. Bmc Bioinformatics. 16, 169

\section{Tables}

Table 1. Summary of mRNA changes observed during XBP1s induction, ER stress induced with $\mathrm{Tg}$ or $\mathrm{Tm}$, and Tg or Tm ER stress together with XBP1 silencing ( $T g$ and $\mathrm{Tm} / X B P 1 \mathrm{~S})$. The results from 3 independent experiments are plotted normalized to GAPDH and RPLPO mRNA levels and expressed as a fold-change ( $\mathrm{FC}$ ) over the respective controls. For induction experiments during ER stress, normalization was performed against non-induced and non-ER stress exposed cells, whereas for silencing experiments the non-induced negative control siRNA transfected cells that were not exposed to ER stress were used as a control. Significant changes $(P$ value $P<0.05)$ are marked with in grey. The Supplemental Table 2AB, contains all the individual values. 


\begin{tabular}{|c|c|c|c|c|c|c|c|c|}
\hline Gene & $\begin{array}{l}\text { Number } \\
\text { of } \\
\text { XBP1 } \\
\text { motifs }\end{array}$ & $\begin{array}{l}\text { Induced } \\
X B P 1 s \\
\text { FC }\end{array}$ & $\begin{array}{l}\text { Tg } \\
\text { FC vs } \\
\text { Ctrl }\end{array}$ & $\begin{array}{l}\mathrm{Tg} / \mathrm{XBP} 1 \\
\text { S FC vs } \\
\text { Ctrl }\end{array}$ & $\begin{array}{l}\text { Tg } \\
\text { /XBP1 } \\
\text { S FC } \\
\text { vs Tg }\end{array}$ & $\begin{array}{l}\text { Tm } \\
\text { FC vs } \\
\text { Ctrl }\end{array}$ & $\begin{array}{l}\text { Tm/XBP1 } \\
\text { S FC vs } \\
\text { Ctrl }\end{array}$ & $\begin{array}{l}\text { Tm/XBP1 } \\
\text { S FC vs } \\
\text { Tm }\end{array}$ \\
\hline$A C L Y$ & 1 & 1.15 & 0.80 & 0.61 & 0.77 & 0.77 & 0.85 & 1.09 \\
\hline ANK2 & 1 & 1.45 & 2.75 & 4.30 & 1.56 & 3.09 & 5.53 & 1.79 \\
\hline ATF3 & 6 & 1.09 & 2.30 & 4.74 & 2.06 & 7.69 & 6.53 & 0.85 \\
\hline$B B C 3$ & 4 & 0.51 & 2.14 & 3.85 & 1.80 & 1.89 & 4.05 & 2.15 \\
\hline CALR & 14 & 1.19 & 1.95 & 1.83 & 0.94 & 1.50 & 1.56 & 1.04 \\
\hline CDK6 & 5 & 1.17 & 0.84 & 0.48 & 0.57 & 1.25 & 0.82 & 0.65 \\
\hline CDKN1A & 10 & 1.18 & 1.00 & 2.87 & 2.86 & 1.05 & 2.77 & 2.65 \\
\hline CHAC1 & 1 & 1.36 & 8.84 & 9.17 & 1.04 & 14.85 & 10.84 & 0.73 \\
\hline DDIT3 & 0 & 1.02 & 8.78 & 12.38 & 1.41 & 19.00 & 13.14 & 0.69 \\
\hline CLIP2 & 12 & 1.13 & 1.01 & 1.72 & 1.71 & 0.92 & 2.25 & 2.43 \\
\hline DHCR24 & 2 & 1.39 & 1.08 & 1.15 & 1.07 & 1.01 & 1.45 & 1.44 \\
\hline DNAJA1 & 4 & 1.13 & 0.72 & 0.59 & 0.82 & 0.72 & 0.86 & 1.19 \\
\hline$D N A J B 2$ & 4 & 0.96 & 1.41 & 1.62 & 1.15 & 1.18 & 1.81 & 1.53 \\
\hline$D N A J B 9$ & 3 & 1.67 & 6.36 & 4.18 & 0.66 & 6.00 & 2.81 & 0.47 \\
\hline$D S P$ & 2 & 1.33 & 0.70 & 0.78 & 1.11 & 1.04 & 1.22 & 1.18 \\
\hline DUSP5 & 12 & 1.08 & 1.08 & 1.26 & 1.16 & 1.23 & 1.46 & 1.19 \\
\hline DUSP6 & 4 & 1.52 & 1.13 & 1.34 & 1.18 & 1.21 & 2.16 & 1.78 \\
\hline EDEM1 & 7 & 1.71 & 2.64 & 1.90 & 0.72 & 2.24 & 1.18 & 0.53 \\
\hline EGR1 & 1 & 1.09 & 1.18 & 0.55 & 0.47 & 5.10 & 1.19 & 0.23 \\
\hline ERLEC1 & 6 & 1.70 & 1.01 & 0.94 & 0.93 & 1.04 & 1.06 & 1.01 \\
\hline ERN1 & 4 & 0.56 & 1.86 & 3.57 & 1.92 & 1.83 & 2.92 & 1.60 \\
\hline FOXJ2 & 4 & 1.59 & 0.80 & 0.75 & 0.93 & 0.91 & 0.79 & 0.86 \\
\hline GADD45A & 2 & 1.08 & 1.53 & 2.27 & 1.48 & 3.26 & 3.62 & 1.11 \\
\hline GADD45B & 2 & 1.12 & 1.29 & 1.05 & 0.82 & 2.29 & 2.11 & 0.92 \\
\hline HSPA1B & 13 & 0.63 & 1.03 & 1.47 & 1.42 & 0.93 & 1.08 & 1.16 \\
\hline HSPA5 & 11 & 1.10 & 6.46 & 4.26 & 0.66 & 4.18 & 2.59 & 0.62 \\
\hline HSPA6 & 5 & 0.13 & 0.38 & 0.61 & 1.61 & 0.17 & 0.51 & 2.96 \\
\hline
\end{tabular}




\begin{tabular}{|lllllllll|}
\hline HSPA8 & 1 & 1.29 & $\mathbf{0 . 5 7}$ & $\mathbf{0 . 5 2}$ & 0.91 & $\mathbf{0 . 5 3}$ & $\mathbf{0 . 6 7}$ & 1.26 \\
\hline ICAM1 & 4 & 1.06 & $\mathbf{1 . 9 7}$ & $\mathbf{3 . 0 2}$ & 1.53 & 1.24 & $\mathbf{3 . 1 2}$ & $\mathbf{2 . 5 2}$ \\
\hline IL1A & 3 & 1.21 & $\mathbf{2 . 5 9}$ & $\mathbf{5 . 9 1}$ & 2.28 & $\mathbf{2 . 9 7}$ & $\mathbf{3 . 9 5}$ & $\mathbf{1 . 3 3}$ \\
\hline IL6 & 4 & 1.37 & $\mathbf{2 . 3 0}$ & $\mathbf{3 . 0 4}$ & $\mathbf{1 . 3 2}$ & $\mathbf{1 . 5 7}$ & $\mathbf{2 . 0 0}$ & $\mathbf{1 . 2 8}$ \\
\hline MAP3K7CL & 4 & 0.95 & $\mathbf{2 . 1 3}$ & $\mathbf{2 . 3 2}$ & 1.09 & $\mathbf{2 . 3 4}$ & $\mathbf{2 . 2 6}$ & 0.96 \\
\hline NFKB2 & 11 & 1.32 & 1.40 & $\mathbf{1 . 6 9}$ & 1.20 & 1.18 & $\mathbf{1 . 8 5}$ & $\mathbf{1 . 5 6}$ \\
\hline RCAN1 & 6 & 1.13 & $\mathbf{2 . 2 8}$ & $\mathbf{5 . 3 8}$ & $\mathbf{2 . 3 6}$ & $\mathbf{1 . 3 4}$ & $\mathbf{2 . 0 2}$ & $\mathbf{1 . 5 1}$ \\
\hline SEC23B & 3 & $\mathbf{1 . 3 6}$ & $\mathbf{1 . 3 2}$ & 1.07 & $\mathbf{0 . 8 1}$ & 3.27 & 1.24 & 0.38 \\
\hline SNAI1 & 5 & $\mathbf{1 . 5 1}$ & 1.08 & 1.27 & 1.17 & 1.22 & 1.17 & 0.96 \\
\hline TRIB3 & 5 & 1.10 & $\mathbf{3 . 7 9}$ & $\mathbf{3 . 7 9}$ & 1.00 & $\mathbf{2 . 3 4}$ & $\mathbf{2 . 6 1}$ & 1.12 \\
\hline WARS & 3 & $\mathbf{1 . 5 8}$ & 1.54 & $\mathbf{1 . 8 3}$ & $\mathbf{1 . 1 9}$ & 1.44 & $\mathbf{1 . 6 4}$ & 1.14 \\
\hline GADD34 & 14 & $\mathbf{0 . 2 7}$ & $\mathbf{1 . 4 3}$ & $\mathbf{2 . 3 7}$ & $\mathbf{1 . 6 5}$ & $\mathbf{3 . 0 5}$ & $\mathbf{2 . 3 7}$ & $\mathbf{0 . 7 8}$ \\
\hline ZNF432 & 3 & 1.01 & 1.08 & 1.09 & 1.01 & 1.12 & 1.44 & 1.29 \\
\hline XBP1S & & 8.73 & 10.60 & 2.20 & 0.21 & 15.21 & 1.46 & 0.10 \\
\hline
\end{tabular}

Figures 
A
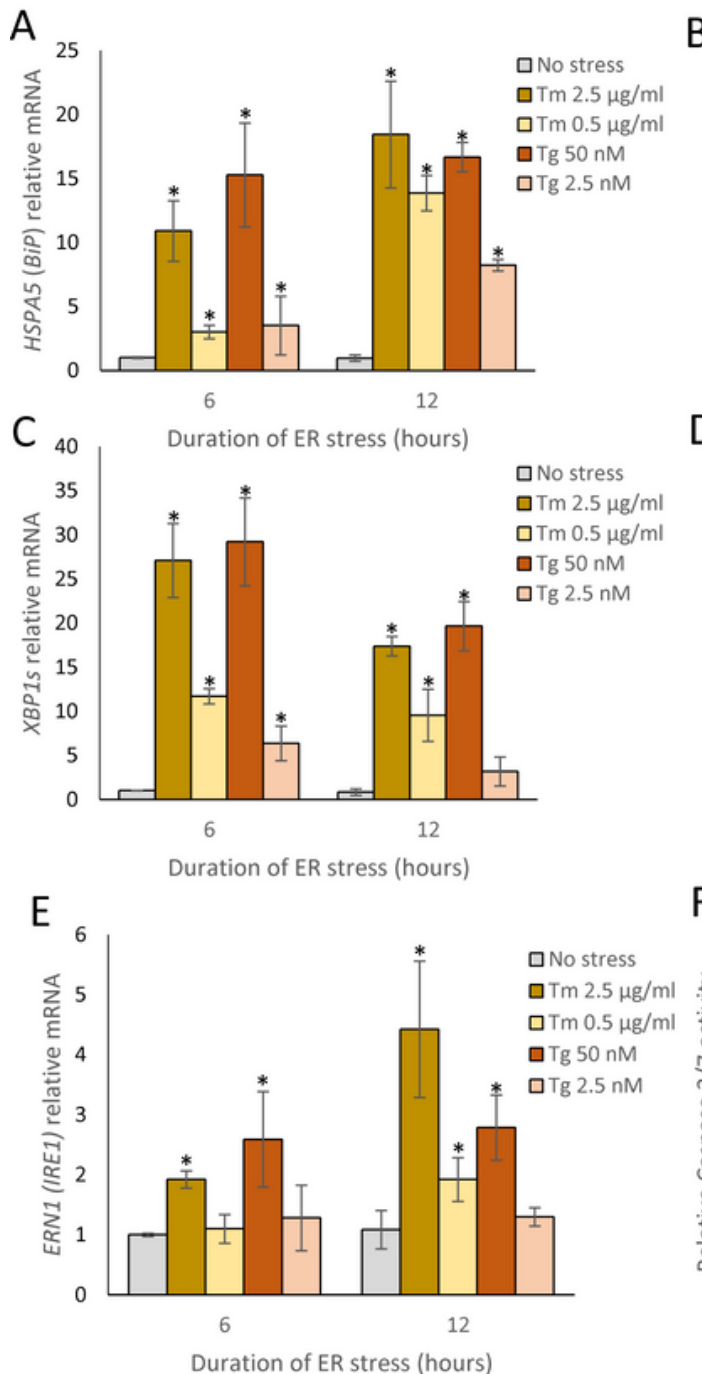

G

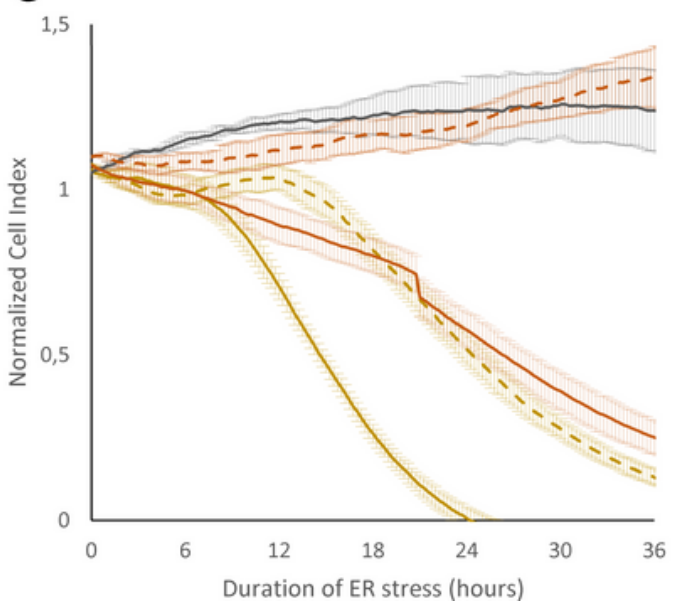

B

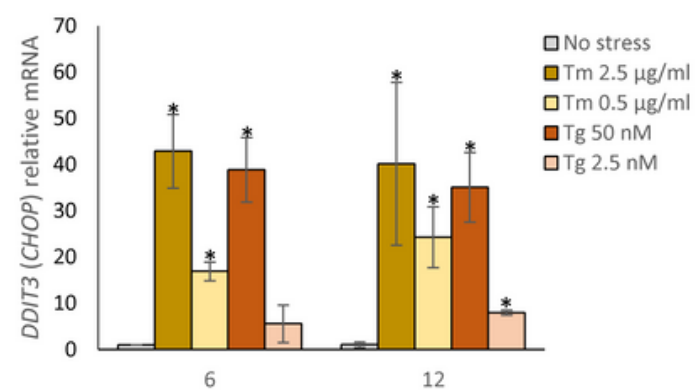

D 18 Duration of ER stress (hours)

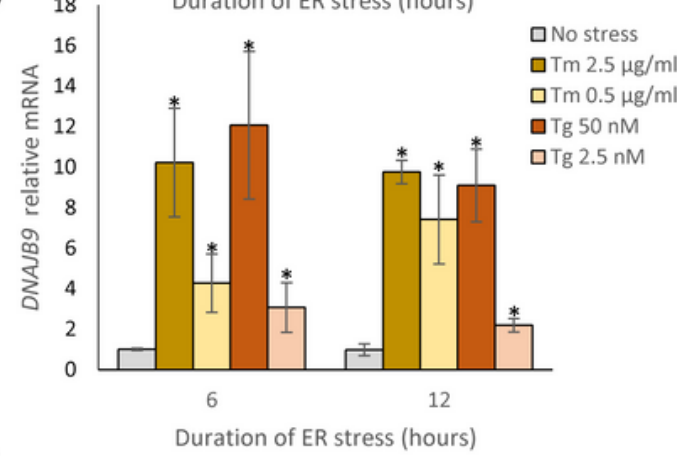

$\mathrm{F}$

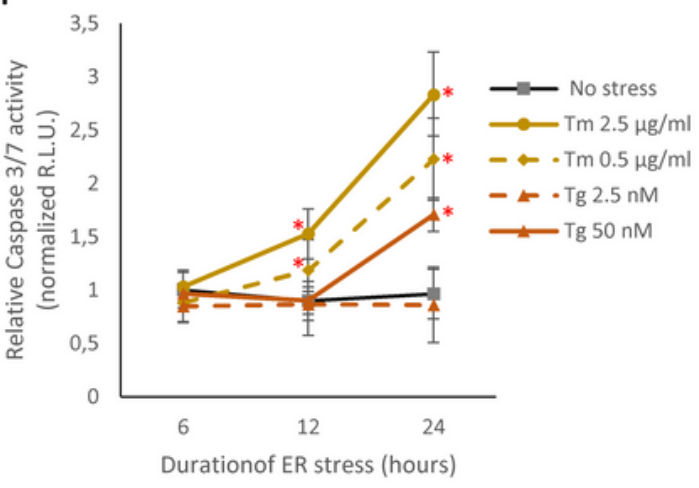

Figure 1

ER stress-induced changes in BIP (A), CHOP (B), XBP1s (C), DNAJB9 (D), IRE1 (E) mRNA levels in HeLa cells. The results from 3 independent experiments $(n=9)$ are plotted normalized to GAPDH and RPLP0 mRNA levels and expressed as a fold-change over the no stress controls. Error bars represent standard deviations. Significant changes ( $P$-value $P<0.05)$ are marked with an asterisk. ER stressors used: Tm $(2.5 \mu \mathrm{g} / \mathrm{ml}), \operatorname{Tm}(0.5 \mu \mathrm{g} / \mathrm{ml}), \operatorname{Tg}(50 \mathrm{nM}))$ and $\mathrm{Tg}(2.5 \mathrm{nM})$. (F) HeLa cells were treated with ER stressors 
$((2.5 \mu \mathrm{g} / \mathrm{ml}), \operatorname{Tm}(0.5 \mu \mathrm{g} / \mathrm{ml}), \operatorname{Tg}(50 \mathrm{nM})$ and $\operatorname{Tg}(2.5 \mathrm{nM}))$ for time points specified. The caspase $3 / 7$ activity was monitored by luminescence and expressed in Relative Light Units (R.L.U.). Cells for each time point were seeded in triplicate, and the experiments repeated three times. Error bars represent standard derivations. (G) The cell conductances (expressed as normalized cell index) were accessed every 15 minutes following a 36-hour treatment with $\operatorname{Tm}(2.5 \mu \mathrm{g} / \mathrm{ml}), \operatorname{Tm}(0.5 \mu \mathrm{g} / \mathrm{ml}), \operatorname{Tg}(50 \mathrm{nM})$ and $\operatorname{Tg}(2.5 \mathrm{nM})$. DMSO was used in the no stress conditions (CTRL). The conductances were normalized to the last value prior to experiment start. Representative results from 3 independent experiments measurements $(n=9)$ are plotted.
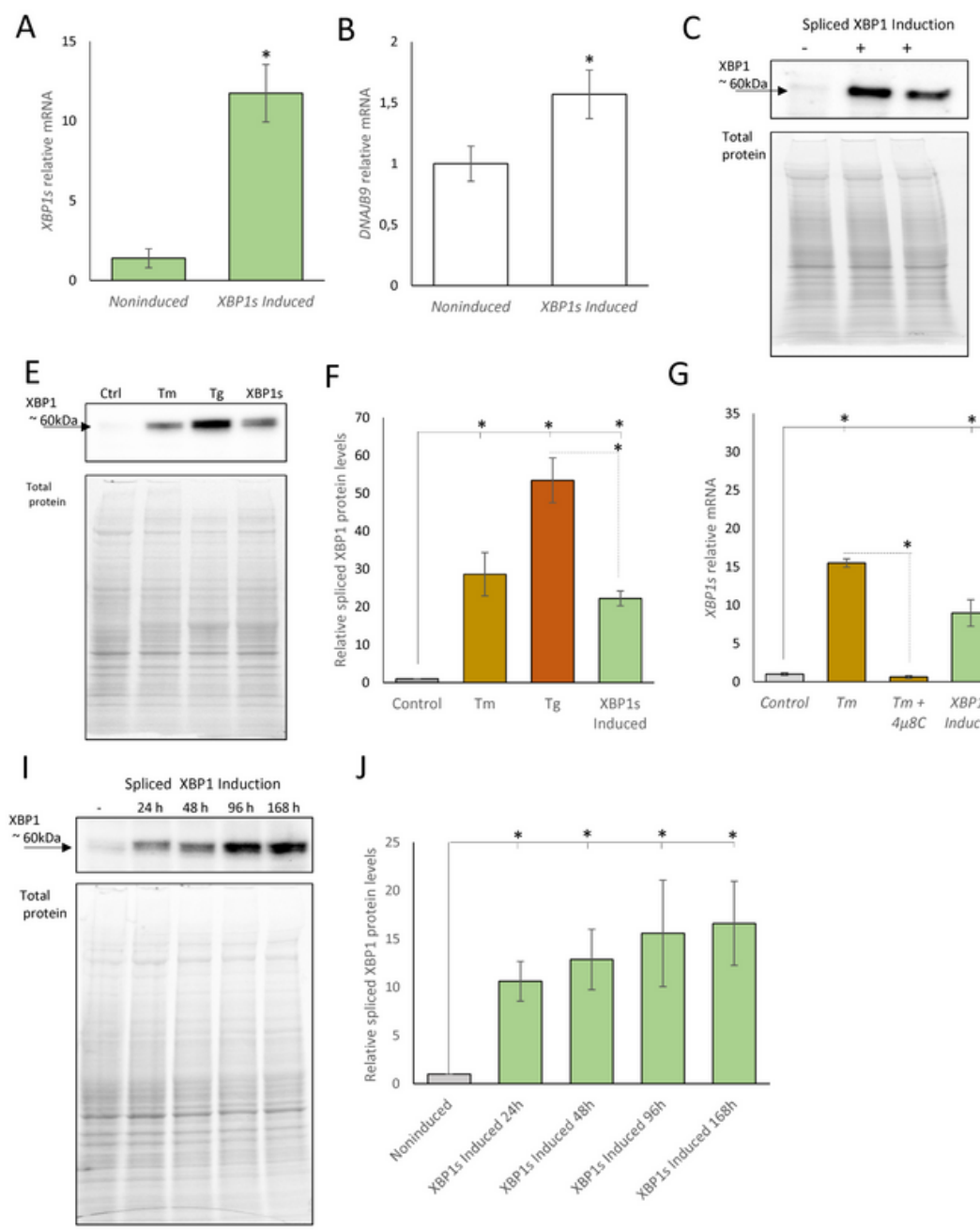

F $\quad$ G

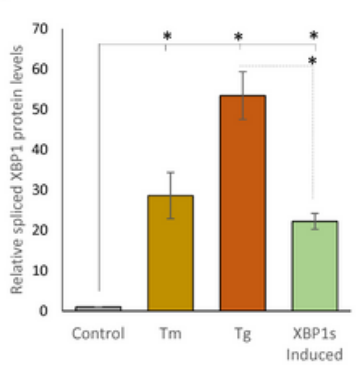

J

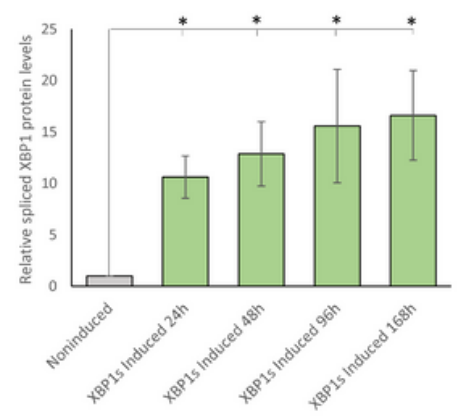

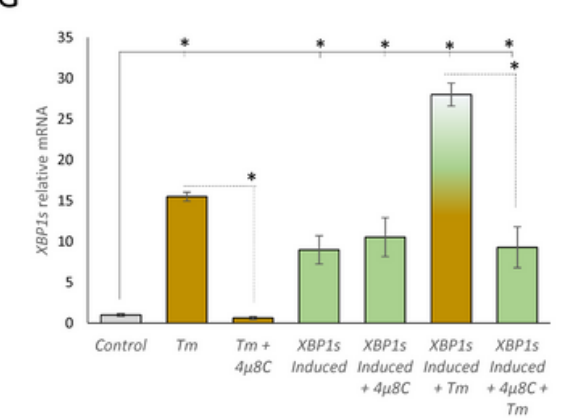

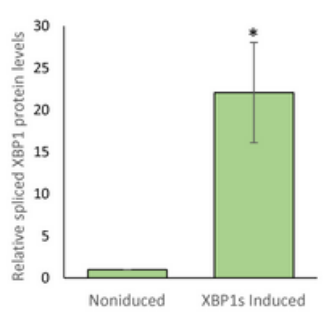

$\mathrm{H}$

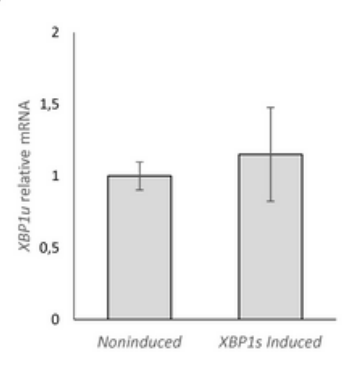

\section{Figure 2}

The HeLa-XBP1s cell line induced for 24 hours accumulates XBP1 (A) and DNAJB9 (B) mRNA. The results from 3 independent experiments $(n=9)$ are plotted normalized to GAPDH and RPLPO mRNA levels and expressed as a fold-change over the noninduced cells. Error bars represent standard deviations. Significant changes (P-value<0.05) are marked with an asterisk. The corresponding changes in XBP1 protein levels were evaluated by Western blot (C) normalized to total protein levels (D) and related noninduced control or evaluated by Western blot and to compared to ER stress induced by Tm (2.5 $\mu \mathrm{g} / \mathrm{ml}), \operatorname{Tg}(50 \mathrm{nM})$ treatment for 6 hours $(E)$ and related to the no stress control $(F)$. ${ }^{*}<<0.05$ was 
considered significant. (G) The exogenous XBP1s mRNA levels were independent IRE1 activity as shown with $4 \mu 8 \mathrm{C}(20 \mu \mathrm{M})$, a specific IRE1 activity inhibitor. Tm was used at $0.5 \mu \mathrm{g} / \mathrm{ml}$ concentration for $6 \mathrm{~h}$. $(\mathrm{H})$ The exogenous XBP1s expression does not lead to accumulation of XBP1u mRNA. The results from 3 independent experiments $(n=9)$ are plotted normalized to GAPDH and RPLPO mRNA levels and expressed as a fold-change over the noninduced cells. Error bars represent standard deviations. Significant changes ( $P$-value $P<0.05)$ are marked with an asterisk. Changes in XBP1 protein levels following induction up to one week (168 hours, media supplemented with doxycycline was exchanged every $48 \mathrm{~h}$ ) were evaluated by Western blot. (I) normalized to total protein levels and the noninduced control (J). Error bars represent standard deviations. Significant changes (P-value $P<0.05)$ are marked with an asterisk.
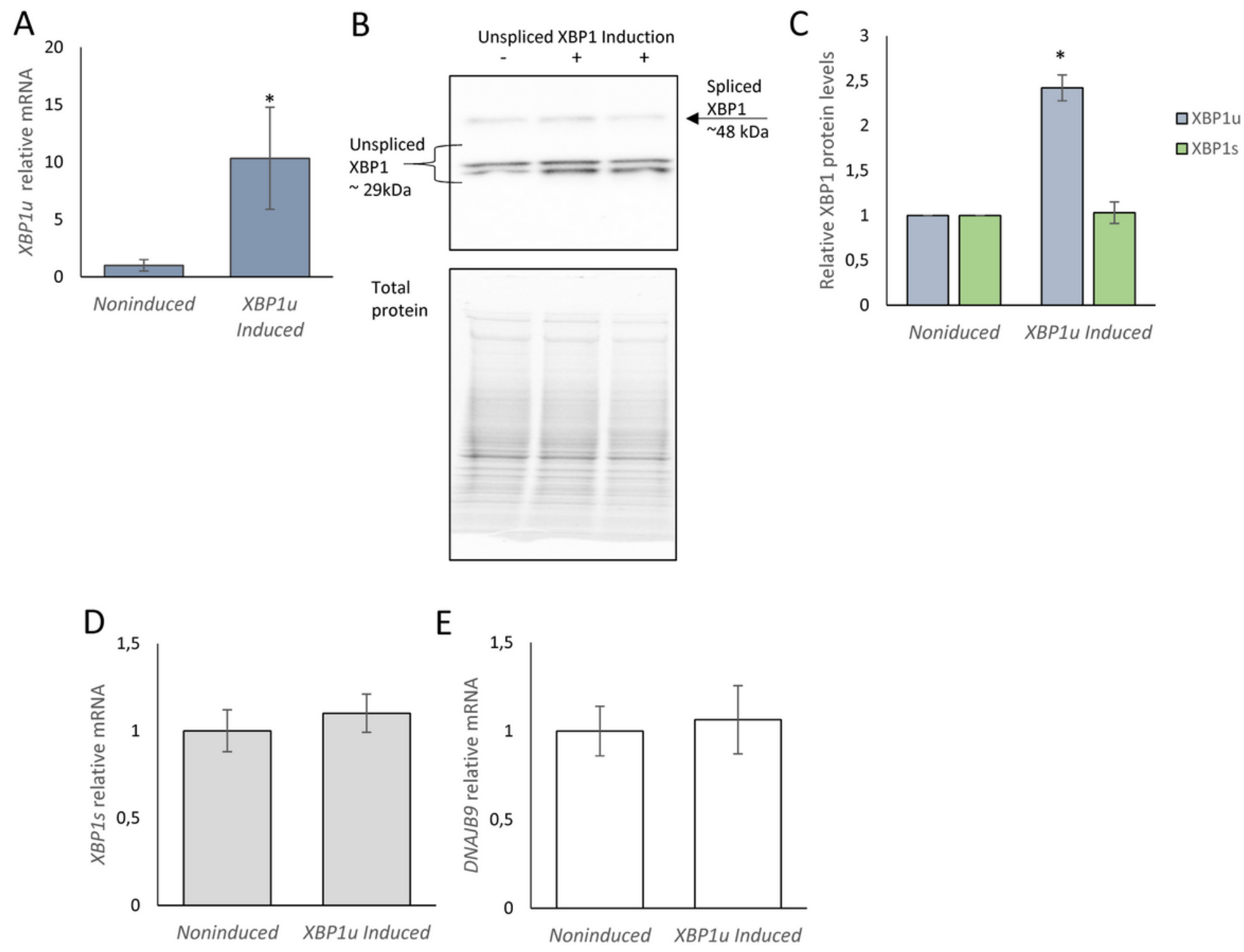

\section{Figure 3}

Upon 24 hours induction, the HeLa-XBP1u cell line accumulates XBP1u mRNA (A). The results from 3 independent experiments $(n=9)$ are plotted normalized to GAPDH and RPLPO mRNA levels and expressed as a fold-change over the noninduced cells. Error bars represent standard deviations. Significant changes $(P$-value $P<0.05)$ are marked with an asterisk. The corresponding changes in unspliced XBP1 and spliced 
XBP1 protein levels were evaluated by Western blot (B) normalized to total protein levels (C) and related noninduced control. ${ }^{*} \mathrm{P}<0.05$ was considered significant. The exogenous XBP1u expression does not lead to accumulation of XBP1s (D) and DNAJB9 (E) mRNA. The results from 3 independent experiments $(n=9)$ are plotted normalized to GAPDH and RPLPO mRNA levels and expressed as a fold-change over the noninduced cells. Error bars represent standard deviations. Significant changes (P-value $<0.05)$ are marked with an asterisk.

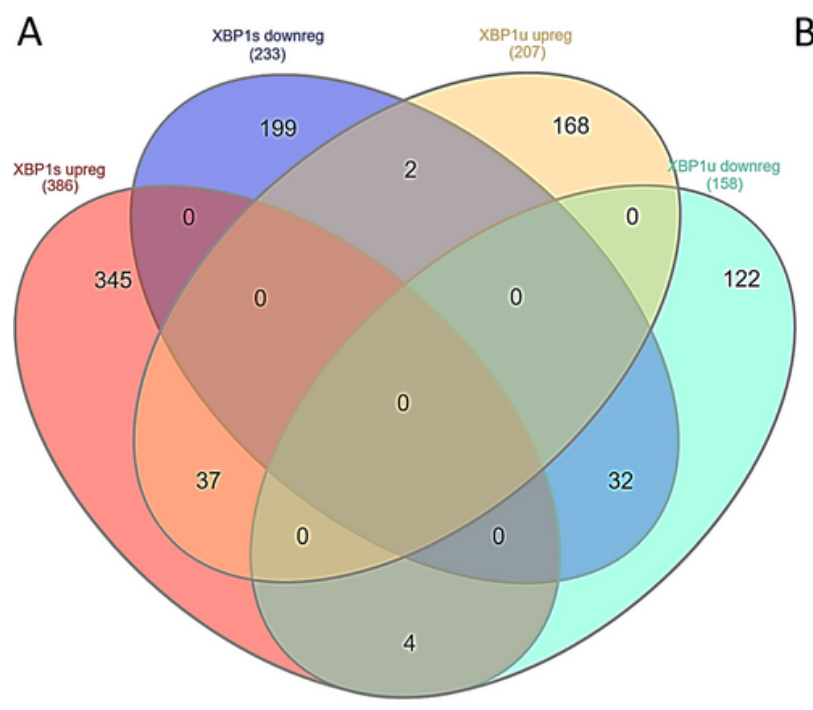

B

XBP1s

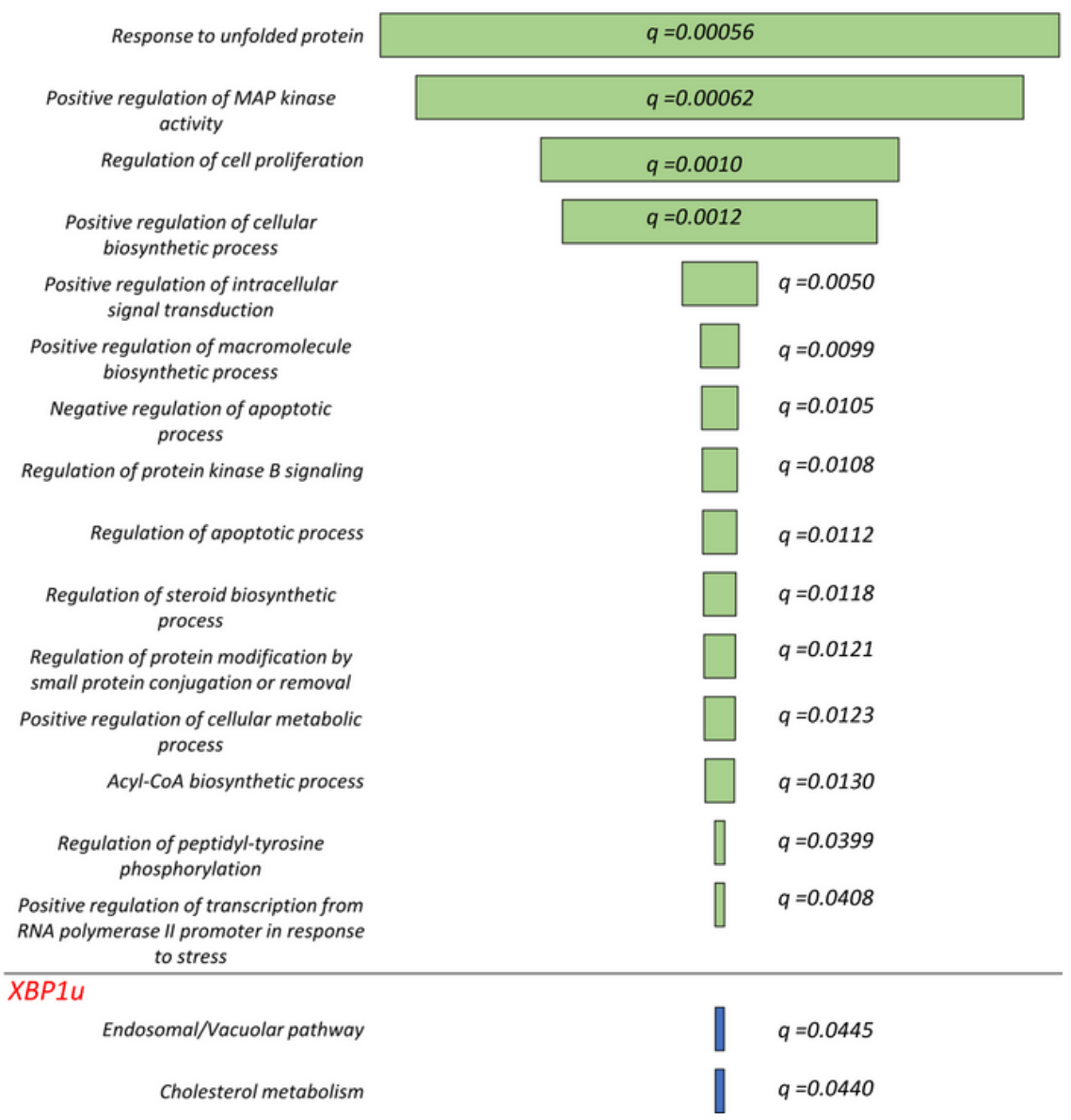

\section{Figure 4}

The impact of the exogenic XBP1u and XBP1s induction on HeLa genome-wide cellular mRNA profiles and their potential functional consequences. The Venn diagram [82] represents the general distribution of mRNAs that were significantly $(\mathrm{P}<0.05)$ affected by XBP1s and XBP1u transgenes - Supplemental Table 2C (A). Transcripts reduced and induced upon XBP1 induction are marked with dark blue and red respectively, whereas mRNAs reduced and induced upon unspliced XBP1 induction are marked with light blue and yellow, respectively. The Gene Ontology assignment of the cellular functions of mRNAs potentially regulated by the spliced XBP1 (XBP1s) or unspliced XBP1 (XBP1u) as assigned by the Enrichr web server - Supplemental Table 2D (B) [38]. The green bar color depicts the q value less than 0.05 . The longer bars have the lower q values. 
A

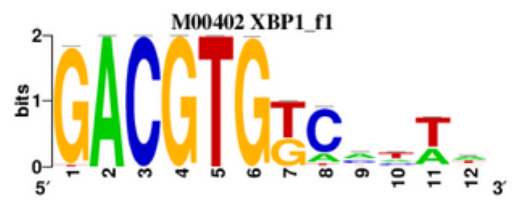

B

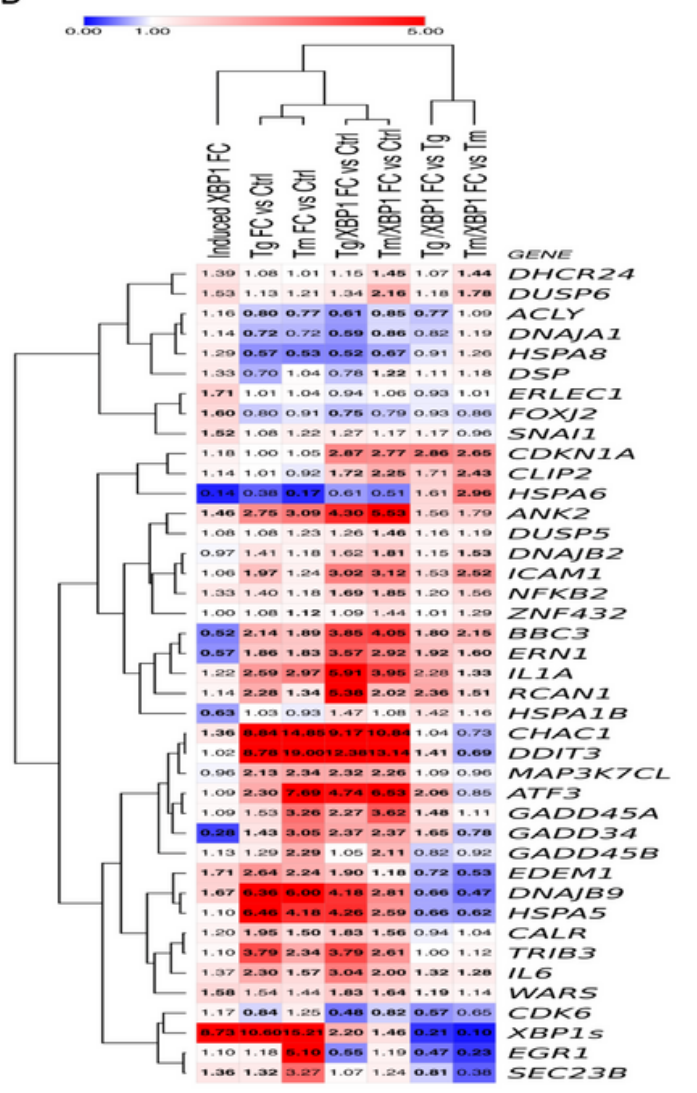

C

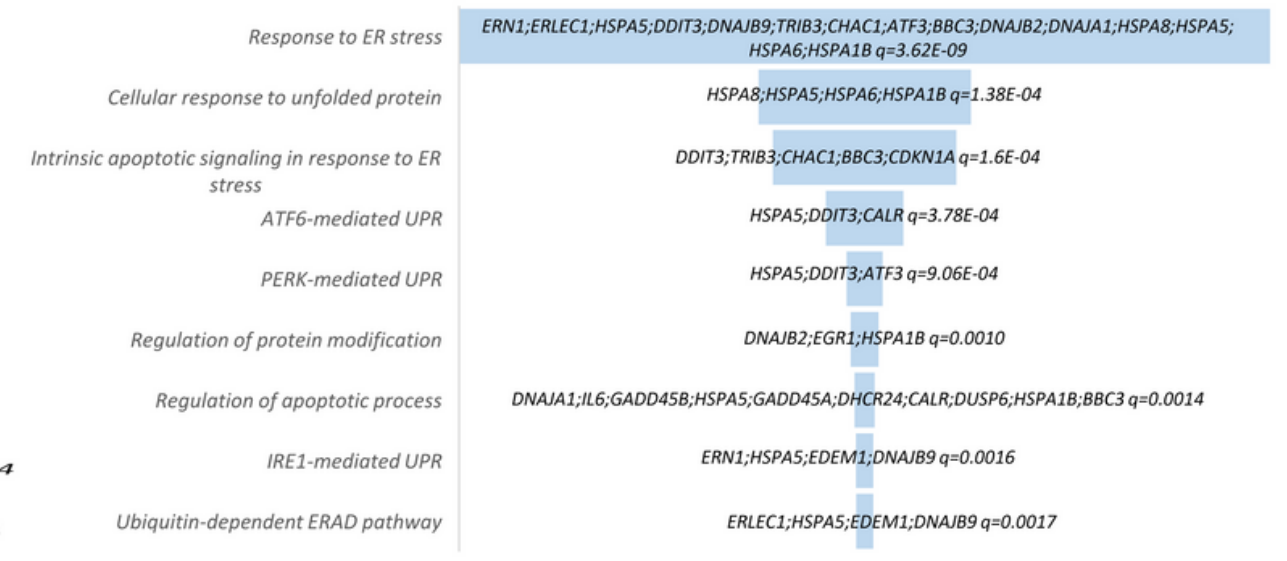

D

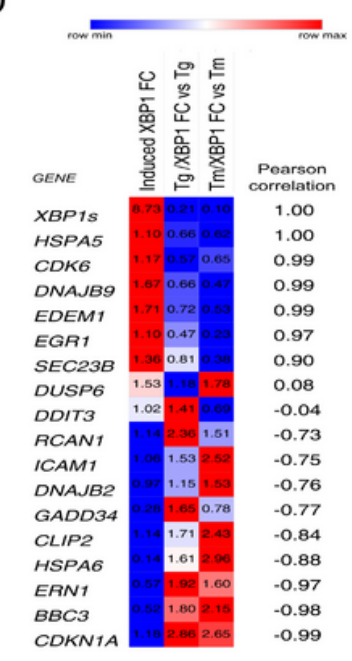

\section{Figure 5}

The heat map representing expression changes of all verified potentially XBP1-dependent genes identified in induced XBP1s expression experiments (Induced XBP1) and separately in silencing XBP1 during mild stress experiments in HeLa cells (Tg/XBP1 S and Tm/XBP1 S). The logo of XBP1 binding motif M00402 (consensus: GACGTGkCmtww, where $k=\mathrm{G}$ or $\mathrm{T} ; \mathrm{m}=\mathrm{A}$ or $\mathrm{C}$; $\mathrm{w}=\mathrm{A}$ or $\mathrm{T}$ ) from the Hocomoco v. 9 motif library (A). Heat maps were generated and organized according to hierarchical clustering of expression changes with the Morpheus software (Morpheus, https://software.broadinstitute.org/morpheus) (B). FC depicts "fold change", Tm - tunicamycin $0.5 \mu \mathrm{g} / \mathrm{ml}$ induced ER stress for $6 \mathrm{~h}, \mathrm{Tg}$ - thapsigargin $2.5 \mathrm{nM}$ induced ER stress for $6 \mathrm{~h}$, whereas Tm/XBP1 S and Tg/XBP1 S depict XBP1 silencing in each of these stress models. The Enrichr webserver (https://amp.pharm.mssm.edu/Enrichr/) was applied to assign the qPCR results into the "Gene Ontology Biological Process" categories with a selection based on a q value $\mathrm{q}<0.05(\mathrm{C})$. Heat map representing the mRNAs that display the most correlated changes with XBP1s mRNA levels as calculated by Pearson correlations (D). The heat maps were generated and organized with the Morpheus software (Morpheus, https://software.broadinstitute.org/morpheus). 


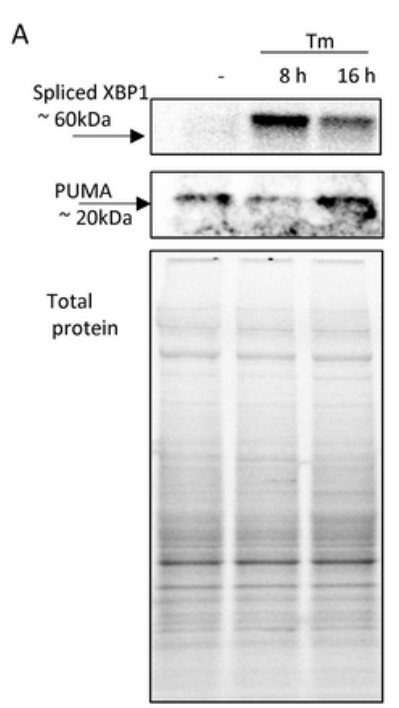

D

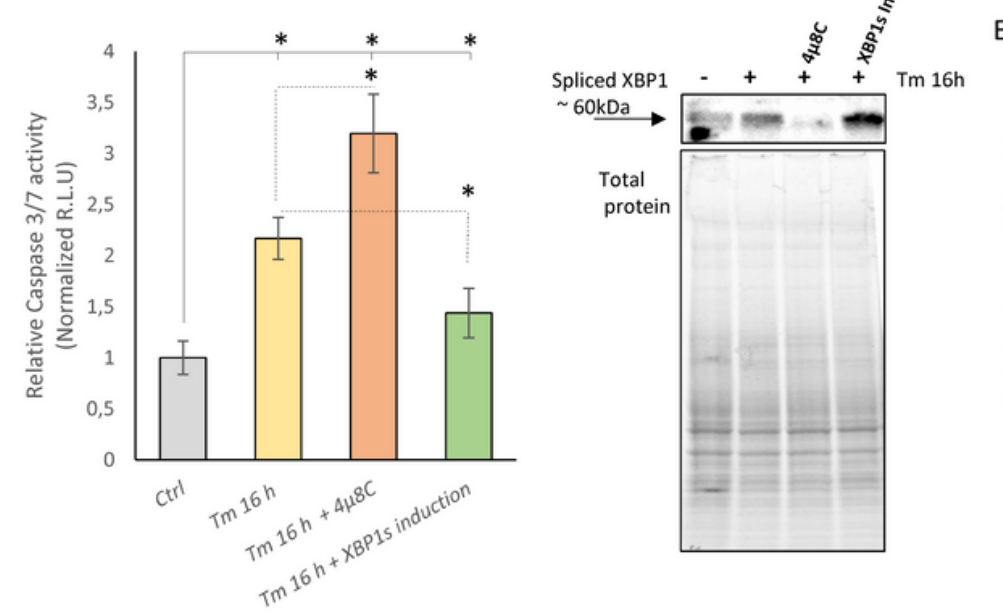

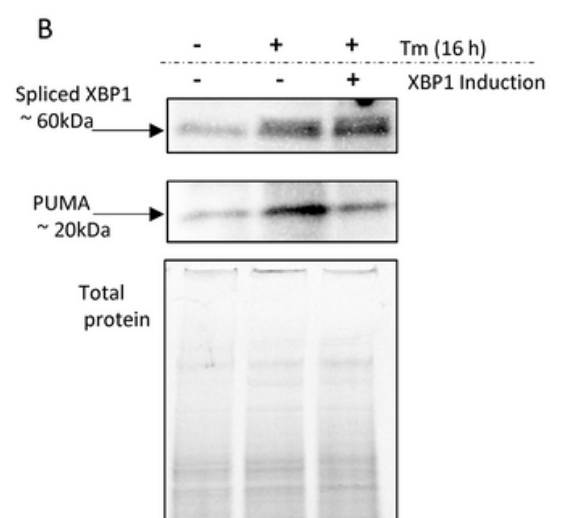
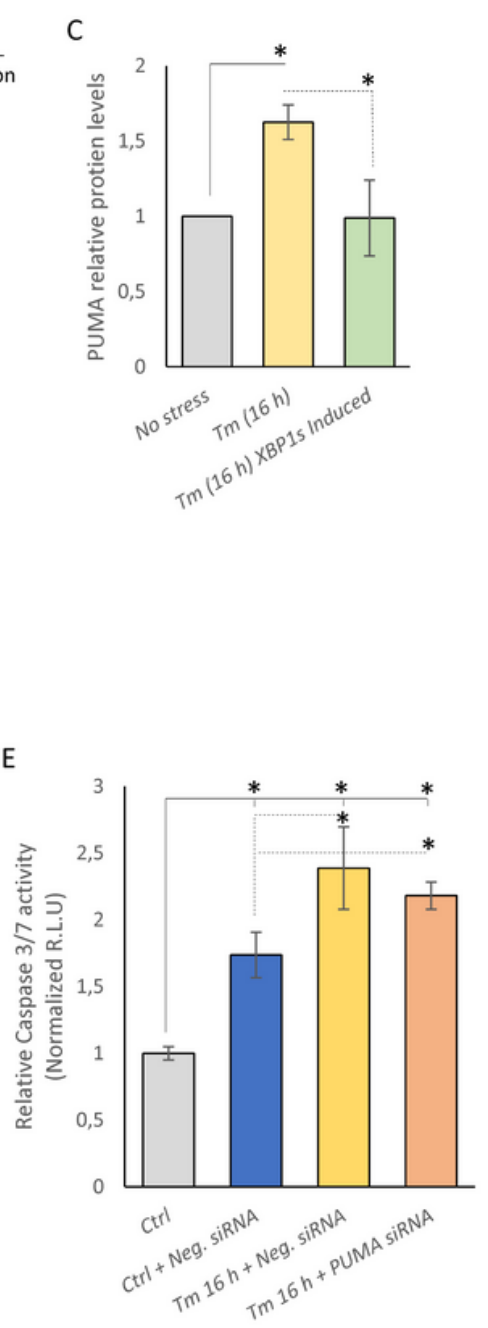

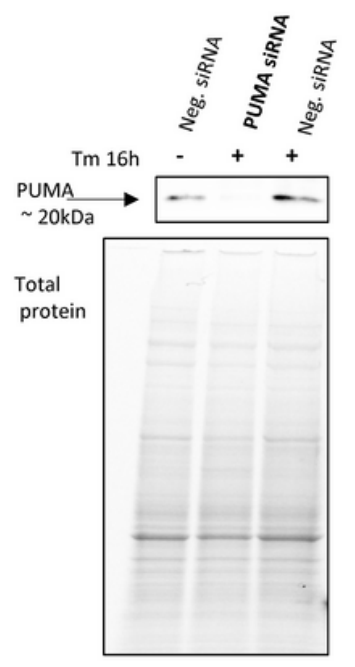

\section{Figure 6}

The 24 hours induction of XBP1s is accompanied by reduced PUMA protein levels and lower Caspase 3/7 activity in Tm treated HeLa cells. Representative changes in XBP1 and PUMA protein levels in HeLa cells treated with $\operatorname{Tm}(2.5 \mu \mathrm{g} / \mathrm{ml})$ for 8 and 16 hours as evaluated by Western blot (A). The changes in XBP1 and PUMA protein levels in XBP1s-induced and -noninduced HeLa cells treated with $\operatorname{Tm}(2.5 \mu \mathrm{g} / \mathrm{ml}) 16$ hours were evaluated by Western blot (B) normalized to total protein levels and related to the noninduced, no stress control (C), and * $P<0.05$ was considered significant. XBP1s-induced ( 24 hours) and noninduced HeLa cells were treated with $\operatorname{Tm}((2.5 \mu \mathrm{g} / \mathrm{ml})$ for 16 hours in the presence or absence of $4 \mu 8 \mathrm{C}$ $(20 \mu \mathrm{M})$, a specific IRE1 activity inhibitor. The caspase $3 / 7$ activity was monitored by luminescence and expressed in Relative Light Units (R.L.U.). Cells for each time point were seeded in triplicate, and the experiments repeated three times. Error bars represent standard derivations and $* \mathrm{P}<0.05$ was considered significant. The corresponding changes in XBP1 protein levels were evaluated by Western blot (D). HeLa cells were treated with $\mathrm{Tm}(2.5 \mu \mathrm{g} / \mathrm{ml})$ for 16 hours in the presence or absence of a specific siRNA against BBC3 (PUMA). The caspase 3/7 activity was monitored by luminescence and expressed in Relative Light Units (R.L.U.). Cells for each time point were seeded in triplicate, and the experiments repeated three 
times. Error bars represent standard derivations, ${ }^{\star} P<0.05$ was considered significant. The corresponding changes in PUMA protein levels were evaluated by Western blot $(\mathrm{E})$.

\section{Supplementary Files}

This is a list of supplementary files associated with this preprint. Click to download.

- FigureS1.tif

- SupplementalTable1.TaqManprobesids.xlsx

- SupplementalTable2..xlsx 